\title{
A MATHEMATICAL MODEL ON THE OPTIMAL NUMBER OF HYDROGEN STATIONS WITH RESPECT TO THE DIFFUSION OF FUEL CELL VEHICLES
}

\author{
Yudai Honma Osamu Kurita \\ Keio University
}

(Received April 29, 2007; Revised November 16, 2007)

\begin{abstract}
In this paper, the optimal numbers of gas and hydrogen stations are examined. Recently, the possibility of gasoline vehicles being replaced with fuel cell vehicles (FCV) is being examined in the coming hydrogen society. The realization of this scenario however needs a large number of hydrogen refueling stations, which hardly exist at the present. We first calculate the optimal number of hydrogen stations to minimize the sum of two types of cost: 1) operation cost of hydrogen stations and 2) transportation cost of FCVs to the nearest stations. Next, we incorporate the diffusion rate of FCVs into the model to determine the optimal number of gas stations and that of hydrogen stations simultaneously. We also provide an advanced model that considers hybrid stations, with which both gasoline and FCVs can refuel. These models clarify that the optimal number of total stations varies with the diffusion rate of FCVs. If only gas and hydrogen stations are assumed, more stations are needed in the transition period. If hybrid stations are introduced, the number of total stations takes minimum value during the transition period. Moreover, the optimal solution indicates that all stations should become hybrid stations in the middle of the transition. Finally, the models are applied to Yokohama City in Japan and the solutions of the models are examined.
\end{abstract}

Keywords: Facility planning, energy, fuel cell vehicle, dịfusion rate, hydrogen stations, Yokohama City

\section{Introduction}

In this paper, we focus on Hydrogen stations which are facilities for fuel cell vehicles (FCVs) to refuel hydrogen. Particularly, we consider the optimal number of hydrogen stations in a region with respect to the diffusion level of FCVs. Our main objective is to clarify how the diffusion rate of FCVs and the size of region affect the optimal number of stations.

Since the twentieth century, we have been consuming massive amounts of fossil fuels. It is not an exaggeration to say that the evolution of our culture has been achieved by utilizing this energy resources [28]. However, rapid consumption in past a hundred years has caused several serious problems at the same time.

One of the most important issues is global warming. In recent years, an increase in the average surface temperature and a rising sea level has been observed, and their influences on the many physical and biological systems are of concern [3]. These climate changes over last 50 years are very likely to be attributable to human activities - especially carbon dioxide $\left(\mathrm{CO}_{2}\right)$ emissions by the combustion of fossil fuels. According to Intergovernmental Panel on Climate Change, projections in climate models result in an increase in a globally averaged surface temperature of 1.4 to $5.8^{\circ} \mathrm{C}$ over the period 1990 to 2100 . In addition, the disruption of ecosystems, drought, and pest infestations are expected to increase [10].

Depletion of fossil-fuel resources is another problem that we are facing [27]. Specifically, 
the exhaustion of conventional oil has been warned by a great number of institutes and scientists. Although extremely pessimistic projections, for example that the production of oil will peak between 2010 and 2020 [16], are heard only infrequently, it is evident that these resources are finite and must be replaced eventually.

These facts are particularly pressing in the transportation sector, which still relies almost exclusively on oil [7]. That is to say, mitigation of $\mathrm{CO}_{2}$ emissions and departure from dependence on oil is strongly expected in the sector. Hydrogen and fuel cells are vital technologies which make independence from oil a reality [9]. More precisely, utilizing hydrogen as an energy carrier, we use fuel cells as motive devices in transportation. By combining hydrogen and oxygen in the systems, a fuel cell can generate electricity and only emits water and heat. This principal is a reverse reaction of water electrolysis [21].

FCV is a kind of electric vehicle powered by a fuel cell. Since FCVs emit only water vapor, they can be relied upon to reduce $\mathrm{CO}_{2}$. In addition, FCVs are nearly three times as efficient as gasoline vehicles and contribute to saving energy [8]. However, there are barriers to getting them incorporated into our daily lives. Price is one of the issues of FCVs. Although FCVs have already been commercialized by some auto manufacturers, one FCV costs 100 million yen (nearly 1 million dollars) now. This is a result of the price of the fuel cell itself. In addition, we need to build huge hydrogen infrastructures to expand the use of FCVs. As a method of supplying hydrogen to FCVs, direct hydrogen type, which is supplied hydrogen directly, and onboard reforming type, which supplies fuel other than hydrogen and produces hydrogen with an on-board reformer, have been developed. At present, the direct hydrogen type is considered to be the mainstream technology in terms of energy efficiency and $\mathrm{CO}_{2}$ reduction. Therefore, FCVs have to refuel hydrogen directly. This fact indicates that a great number of hydrogen stations is needed in cities, yet, there are only 100 hydrogen stations in the world to date (10 stations exist in Tokyo metropolitan area). As a consequence, how we construct hydrogen stations is an essential issue.

For safety purposes, the existing hydrogen stations are all operated separately from gas stations. However, in scenarios demonstrated by some institutes, hybrid stations, which are facilities for both gasoline vehicles and FCVs refueling, are expected to be introduced in early stages $[20,29]$. That is to say, since the number of FCVs is not sufficient, it is more efficient to append equipment for refueling hydrogen to existing gas stations.

The necessary number of hydrogen stations has been also calculated. In Japan, for example, The Agency for Natural Resources and Energy estimated the future prospects of the number of hydrogen stations, and concluded that 4000 hydrogen stations are needed by 2020 [6]. These estimations are derived from a simple calculation, namely the number of FCVs divided by the capacity of one hydrogen station. However, we should be cautious of the relation of the trade-off between operation cost of hydrogen stations and transportation cost of FCVs. If there are only a few stations in a region, FCVs need to move long distance for refueling. On the other hand, If there are too many stations, the cost of operating stations would be unnecessarily high. To incorporate this trade-off, we have to consider the size of the region explicitly, which relates to the transportation cost of FCVs.

The relation of trade-off stated above holds true not only for hydrogen stations but any kind of facilities which customers are supposed to visit. Thus, it has been discussed in a number of research papers (e.g. Stephan [22,23], Palmer [19], Gusein-Zade [5], Suzuki [25], and Kurita [14]). Although the exact specifications of these models are different, they all clarify the relationship between the number of facilities, the size of a region, and the number of customers. We adopt Stephan and Kurita as a basic model of this study. In latter sections of this paper, we generalize the model to treat multiple types of facilities (i.e. gas, hydrogen, 
and hybrid stations) simultaneously. Generalizations with respect to multi-types have been formulated only by Docmeci [2] and Suzuki [24], which incorporate a hierarchical structure of service system.

This paper is organized as follows. In Section 2, we will discuss the optimal number of hydrogen station to understand the basic idea of the study. In accordance with Stephan and Kurita, we formulate a model to minimize the sum of operation cost and transportation cost. Then, we propose a model for gas station and hydrogen station on the assumption that both gasoline vehicles and FCVs exist (Section 3). Our concern is how the diffusion rate of FCVs affects the optimal number of stations. The main result in this section is that the maximum value of the number of total stations is observed in the middle of the transition period. In Section 4, an advanced model which considers hybrid stations will be presented. From the model, the effects of introduction of hybrid stations are confirmed; The number of total stations could be reduced and all stations become hybrid station in transition period. In Section 5, finally, all models stated above are applied to Yokohama City in Japan and differences in term of the total cost are examined.

\section{Optimal Number of Hydrogen Stations}

First, we describe a basic model which optimizes the number of hydrogen stations in a region. This model will be helpful for a better understanding of the concept of the study.

\subsection{Assumptions}

Let us assume a region whose size is $S$ and also assume there are $M$ FCVs. For simplicity, we suppose that all FCVs are uniformly distributed in the region. Then, we plan to build some hydrogen stations for FCVs refueling. All FCVs will visit the nearest hydrogen station from each distributed point only for refueling. That is to say, we prohibit refueling by halfway stop to other destinations in this model.

Since all FCVs refuel at the nearest hydrogen station, the catchment areas of hydrogen stations are expressed by Voronoi tessellation. For the sake of simplicity, we suppose that each catchment area has same size. Consequently, the size of each catchment area is given by $S / n_{\mathrm{H}}$, where $n_{\mathrm{H}}$ is the number of hydrogen stations in the region.

\subsection{Cost definition}

Let us define two types of cost which are taken into account for the operation of stations and the transportation of vehicles. First of all, we will consider the operation cost of hydrogen stations. In this research, we simply assume that the operation cost of one hydrogen station is $b_{\mathrm{H}}$ [yen/year]. Now, there are $n_{\mathrm{H}}$ hydrogen stations in the region, then total operation cost of hydrogen stations $f^{\mathrm{i}}\left(n_{\mathrm{H}}\right)$ is given by

$$
f^{\mathrm{i}}\left(n_{\mathrm{H}}\right)=b_{\mathrm{H}} \cdot n_{\mathrm{H}}
$$

We next address transportation cost of FCVs. In this paper, we calculate the cost based on "average distance" from uniformly distributed FCVs to the nearest station. As previously mentioned, the size of each station's catchment area is $S / n_{\mathrm{H}}$, so the scale of each area is calculated by $\sqrt{S / n_{\mathrm{H}}}$. Let us recall that the dimension of the area size is given by $\left[\mathrm{km}^{2}\right]$. Hence, the average distance to the nearest station should be proportional to $\sqrt{S / n_{\mathrm{H}}}$, whose dimension is $[\mathrm{km}]$. Therefore, the average distance from FCVs to the nearest station $\bar{d}_{\mathrm{H}}^{\mathrm{i}}\left(n_{\mathrm{H}}\right)[\mathrm{km}]$ is approximately given by

$$
\bar{d}_{\mathrm{H}}^{\mathrm{i}}\left(n_{\mathrm{H}}\right)=\kappa \sqrt{S / n_{\mathrm{H}}}
$$


where $\kappa$ is a parameter which depends on (i) the definition of distance, (ii) the shape of area, (iii) the location of stations ${ }^{1}$. If each FCV refuels $\nu_{\mathrm{H}}$ times per year, the total transportation distance of one FCV can be calculated as $2 \nu_{\mathrm{H}} \bar{d}\left(n_{\mathrm{H}}\right)$ (the distance has been doubled to represent roundtrips). Furthermore, we define the following parameter:

$$
\alpha=[\text { transportation cost per unit distance }][\mathrm{yen} / \mathrm{km}] \text {. }
$$

Multiplying $\alpha$ and the total transportation distance, we now derive the total transportation cost per vehicle (per year) $2 \alpha \nu_{\mathrm{H}} \bar{d}\left(n_{\mathrm{H}}\right)$. If there are $M$ FCVs in the region, then the total transportation cost $g^{\mathrm{i}}\left(n_{\mathrm{H}}\right)$ is expressed as follows:

$$
\begin{aligned}
g^{\mathrm{i}}\left(n_{\mathrm{H}}\right) & =M \times 2 \alpha \nu_{\mathrm{H}} \bar{d}_{\mathrm{H}}^{\mathrm{i}}\left(n_{\mathrm{H}}\right) \\
& =k_{\mathrm{H}} M \sqrt{S / n_{\mathrm{H}}}
\end{aligned}
$$

where $k_{\mathrm{H}}=2 \alpha \nu_{\mathrm{H}} \kappa$.

\subsection{Minimization of total cost}

Let us define total cost $T^{\mathrm{i}}\left(n_{\mathrm{H}}\right)$ in the region as the sum of $f^{\mathrm{i}}\left(n_{\mathrm{H}}\right)$ and $g^{\mathrm{i}}\left(n_{\mathrm{H}}\right)$ :

$$
T^{\mathrm{i}}\left(n_{\mathrm{H}}\right)=f^{\mathrm{i}}\left(n_{\mathrm{H}}\right)+g^{\mathrm{i}}\left(n_{\mathrm{H}}\right) .
$$

The objective in the present section is to obtain the optimal number of hydrogen stations $n_{\mathrm{H}}^{\mathrm{i}}{ }^{*}$ which minimizes the total $\operatorname{cost} T^{\mathrm{i}}\left(n_{\mathrm{H}}\right)$. This idea is based on social optimization, and would be different from the economic principle observed in the real world. However, hydrogen stations are huge infrastructures we will all continue to use, and they would be economically supported by public sectors. Thus, it is essential to clarify the state which is socially optimal.

Let us consider the following mathematical programming problem:

$$
\begin{array}{ccc}
\text { [Problem i* } & \text { min. } & T^{\mathrm{i}}\left(n_{\mathrm{H}}\right) \\
& \text { s.t. } & n_{\mathrm{H}} \geq 0 .
\end{array}
$$

Normally, $n_{\mathrm{H}}$ is an integer because it is the number of stations. In this paper, we however regard $n_{\mathrm{H}}$ as a real number to clarify features of the optimal solution. As a simple derivation, we know that $T^{\mathrm{i}}\left(n_{\mathrm{H}}\right)$ gives us

$$
\left.\begin{array}{r}
\lim _{n_{\mathrm{H}} \rightarrow+0} T^{\mathrm{i}}\left(n_{\mathrm{H}}\right)=+\infty ; \\
\lim _{n_{\mathrm{H} \rightarrow+\infty}} T^{\mathrm{i}}\left(n_{\mathrm{H}}\right)=+\infty ;
\end{array}\right\}
$$

and

$$
T^{\mathrm{i}^{\prime \prime}}\left(n_{\mathrm{H}}\right)=\frac{3}{4} k_{\mathrm{H}} M S^{1 / 2} n_{\mathrm{H}}^{-5 / 2} \geq 0
$$

because $n_{\mathrm{H}} \geq 0$. Hence, $T^{\mathrm{i}}\left(n_{\mathrm{H}}\right)$ must contain the optimal solution. Therefore, we derive the optimal solution $n_{\mathrm{H}}^{\mathrm{i}}$ by solving the first order condition

$$
T^{\mathrm{i}^{\prime}}\left(n_{\mathrm{H}}\right)=b_{\mathrm{H}}-\frac{1}{2} k_{\mathrm{H}} M S^{1 / 2} n_{\mathrm{H}}^{-3 / 2}=0
$$

\footnotetext{
${ }^{1}$ When a region is regularly tessellated, the value of $\kappa$ is $0.37 \sim 0.40$. More precisely, $\kappa$ is 0.3772 for the hexagon, 0.3826 for the square, and 0.4037 for the triangle [22].
} 
and we get $n_{\mathrm{H}}^{\mathrm{i}}$ as follows:

$$
n_{\mathrm{H}}^{\mathrm{i}}{ }^{*}=\left(\frac{k_{\mathrm{H}} M}{2 b_{\mathrm{H}}}\right)^{2 / 3} S^{1 / 3} .
$$

As discussed in previous research, the optimal solution ${ }^{2}$ is in proportion to two-thirds power of $M$ and one-third power of $S$. From (2.1), we obtain the following feature:

[feature 1]

The optimal number of hydrogen stations is proportional to the number of FCVs to two-thirds power and the size of region to one-third power.

\section{Optimal Number of Gas and Hydrogen Stations}

In Section 2, we considered the circumstance that only FCVs existed. However, FCVs must be introduced gradually by replacing gasoline vehicles. This fact means that both gasoline vehicles and FCVs coexist in the transition period. Then, in this section, we improve the previous model and propose a model which considers not only hydrogen stations and FCVs but gas stations and gasoline vehicle. We treat hybrid stations--namely stations that gasoline vehicles and FCVs can refuel-in the next section.

\subsection{Assumptions}

Suppose a region whose size is $S$ and that there are some gasoline vehicles and FCVs in the region. We assume that the number of total vehicles is predetermined as $M$. In addition, let $q$ denote the diffusion rate of FCVs - namely the ratio of FCVs to all vehicles $(0 \leq q \leq 1)$. Hence, there are $(1-q) M$ gasoline vehicles and $q M$ FCVs in the region. For simplicity, we also assume that gasoline vehicles and FCVs are distributed uniformly and respectively.

Now we consider building $n_{\mathrm{G}}$ gas stations and $n_{\mathrm{H}}$ hydrogen stations. It is assumed that all gasoline vehicles will refuel at the nearest gas stations while FCVs will refuel at the nearest hydrogen stations (all vehicles are prohibited to make a halfway stop at a station on the way to other destinations). Furthermore, let us consider the catchment area of stations. The same as in the previous model, if the size of each catchment area is equal, then the catchment area size of a gas station is given by $S / n_{\mathrm{G}}$, and that of a hydrogen station is $S / n_{\mathrm{H}}$.

\subsection{Cost definition}

Before we formulate the model, we provide operation cost of stations and transportation cost of vehicles as in last section. To begin with, we define operation cost of stations in the region. In a similar manner to the previous model, we simply assume that one gas station $\operatorname{cost} b_{\mathrm{G}}$ [yen/year] to operate and one hydrogen station is $b_{\mathrm{H}}$ [yen/year]. Subscripts $\mathrm{G}$ and $\mathrm{H}$ mean gas and hydrogen respectively. Thus, the total operation cost of stations in the region $f^{\text {ii }}\left(n_{\mathrm{G}}, n_{\mathrm{H}}\right)$ can be calculated as

$$
f^{\mathrm{ii}}\left(n_{\mathrm{G}}, n_{\mathrm{H}}\right)=b_{\mathrm{G}} n_{\mathrm{G}}+b_{\mathrm{H}} n_{\mathrm{H}},
$$

\footnotetext{
${ }^{2}$ It is equivalent that the station density varies directly as two-thirds power of FCV density, because dividing $n_{\mathrm{H}}^{\mathrm{i}}{ }^{*}$ into $S$ yields
}

$$
\frac{n_{\mathrm{H}}^{\mathrm{i}^{*}}}{S}=\left(\frac{k_{\mathrm{H}}}{2 b_{\mathrm{H}}}\right)^{2 / 3}\left(\frac{M}{S}\right)^{2 / 3}
$$


where $n_{\mathrm{G}}$ denotes the number of gas stations and $n_{\mathrm{H}}$ is the number of hydrogen stations.

Next, we consider the transportation cost of vehicles for refueling. In a similar argument to the previous section, we calculate the cost based on "average distance". Average distances are not equal between gasoline vehicles and FCVs, because the number of stations where they can refuel is different. Therefore, we need to calculate them respectively this time. For gasoline vehicles, the size of the catchment area is $S / n_{\mathrm{G}}$, and the scale is $\sqrt{S / n_{\mathrm{G}}}$. On the other hand, for FCVs, the size of the catchment area is given by $S / n_{\mathrm{H}}$, so the scale is $\sqrt{S / n_{\mathrm{H}}}$. Hence, average distance of gasoline vehicles to the nearest station $\bar{d}_{\mathrm{G}}^{\mathrm{ii}}\left(n_{\mathrm{G}}\right)[\mathrm{km}]$ is roughly expressed as

$$
\bar{d}_{\mathrm{G}}^{\mathrm{ii}}\left(n_{\mathrm{G}}\right)=\kappa \sqrt{S / n_{\mathrm{G}}}
$$

Similarly, average distance of FCVs to the nearest station $\bar{d}_{\mathrm{H}}^{\mathrm{ii}}\left(n_{\mathrm{H}}\right)[\mathrm{km}]$ is given by

$$
\bar{d}_{\mathrm{H}}^{\mathrm{ii}}\left(n_{\mathrm{H}}\right)=\kappa \sqrt{S / n_{\mathrm{H}}} \text {. }
$$

As previously mentioned, the value of $\kappa$ depends on the location of stations. Thus, strictly speaking, it varies according to diffusion rate $q$. However, it is implied that the change of $\kappa$ is minimal because $\kappa=0.37 \sim 0.40$ when stations are distributed regularly (even if stations are distributed randomly, $\kappa$ is 0.5 [26]). Therefore, we regard $\kappa$ as constant.

By assuming that each gasoline vehicle refuels $\nu_{\mathrm{G}}$ times and a FCV refuels $\nu_{\mathrm{H}}$ times per year, we can calculate that the average transportation distance of one gasoline vehicle is $2 \nu_{\mathrm{G}} \bar{d}_{\mathrm{G}}^{\mathrm{ii}}\left(n_{\mathrm{G}}\right)$ and that of a FCV is $2 \nu_{\mathrm{H}} \bar{d}_{\mathrm{H}}^{\mathrm{ii}}\left(n_{\mathrm{H}}\right)$. Consequently, average transportation cost is derived by multiplying $\alpha$ and the distance $-2 \alpha \nu_{\mathrm{G}} d_{\mathrm{G}}^{\mathrm{ii}}\left(n_{\mathrm{G}}\right)$ per gasoline vehicle and $2 \alpha \nu_{\mathrm{H}} \overline{\mathrm{H}} \overline{\mathrm{ii}}\left(n_{\mathrm{H}}\right)$ per FCV. As mentioned before, there are $(1-q) M$ gasoline vehicles and $q M$ FCVs in the region, so the total transportation cost $g^{\text {ii }}\left(n_{\mathrm{G}}, n_{\mathrm{H}}\right)$ is given by

$$
\begin{aligned}
g^{\mathrm{ii}}\left(n_{\mathrm{G}}, n_{\mathrm{H}}\right) & =(1-q) M \times 2 \alpha \nu_{\mathrm{G}} \overline{d_{\mathrm{G}}^{\mathrm{ii}}}\left(n_{\mathrm{G}}\right)+q M \times 2 \alpha \nu_{\mathrm{H}} \overline{d_{\mathrm{H}}^{\mathrm{ii}}}\left(n_{\mathrm{H}}\right) \\
& =k_{\mathrm{G}}(1-q) M \sqrt{S / n_{\mathrm{G}}}+k_{\mathrm{H}} q M \sqrt{S / n_{\mathrm{H}}},
\end{aligned}
$$

where $k_{\mathrm{G}}=2 \alpha \nu_{\mathrm{G}} \kappa$ and $k_{\mathrm{H}}=2 \alpha \nu_{\mathrm{H}} \kappa$.

\subsection{Total cost minimization}

Let us define the total cost in the region $T^{\mathrm{ii}}\left(n_{\mathrm{G}}, n_{\mathrm{H}}\right)$ as a sum of $f^{\mathrm{ii}}\left(n_{\mathrm{G}}, n_{\mathrm{H}}\right)$ and $g^{\mathrm{ii}}\left(n_{\mathrm{G}}, n_{\mathrm{H}}\right)$ :

$$
T^{\mathrm{ii}}\left(n_{\mathrm{G}}, n_{\mathrm{H}}\right)=f^{\mathrm{ii}}\left(n_{\mathrm{G}}, n_{\mathrm{H}}\right)+g^{\mathrm{ii}}\left(n_{\mathrm{G}}, n_{\mathrm{H}}\right) \text {. }
$$

The present objective is to derive the optimal number of gas and hydrogen stations $\left\{n_{\mathrm{G}}^{\mathrm{ii} *}, n_{\mathrm{H}}^{\mathrm{ii} *}\right\}$ to minimize the total cost $T^{\mathrm{ii}}\left(n_{\mathrm{G}}, n_{\mathrm{H}}\right)$. We assume that $n_{\mathrm{G}}$ and $n_{\mathrm{H}}$ are real number for simplicity.

Now, let us suppose a mathematical programming problem below:

$$
\begin{array}{lll}
\text { [Problem ii } \left.{ }^{*}\right] & \min . & T^{\mathrm{ii}}\left(n_{\mathrm{G}}, n_{\mathrm{H}}\right) \\
& \text { s.t. } & n_{\mathrm{G}}, n_{\mathrm{H}} \geq 0 .
\end{array}
$$

When $n_{\mathrm{G}}, n_{\mathrm{H}}>0, T^{\mathrm{ii}}\left(n_{\mathrm{G}}, n_{\mathrm{H}}\right)$ is a convex function (Appendix A). Moreover, $T^{\mathrm{ii}}\left(n_{\mathrm{G}}, n_{\mathrm{H}}\right)$ gives us

$$
\left.\begin{array}{r}
\lim _{n_{\mathrm{G}} \rightarrow+0} T^{\mathrm{ii}}\left(n_{\mathrm{G}}, n_{\mathrm{H}}\right)=+\infty ; \\
\lim _{n_{\mathrm{G}} \rightarrow+\infty} T^{\mathrm{ii}}\left(n_{\mathrm{G}}, n_{\mathrm{H}}\right)=+\infty ; \\
\lim _{n_{\mathrm{H}} \rightarrow+0} T^{\mathrm{ii}}\left(n_{\mathrm{G}}, n_{\mathrm{H}}\right)=+\infty ; \\
\lim _{n_{\mathrm{H} \rightarrow+\infty}} T^{\mathrm{ii}}\left(n_{\mathrm{G}}, n_{\mathrm{H}}\right)=+\infty ;
\end{array}\right\} .
$$


Thus, we derive the optimal solution by solving the first order conditions

$$
\begin{aligned}
& \frac{\partial T^{\mathrm{ii}}}{\partial n_{\mathrm{G}}}=b_{\mathrm{G}}-\frac{1}{2}(1-q) M k_{\mathrm{G}} S^{1 / 2} n_{\mathrm{G}}^{-3 / 2}=0, \\
& \frac{\partial T^{\mathrm{ii}}}{\partial n_{\mathrm{H}}}=b_{\mathrm{H}}-\frac{1}{2} q M k_{\mathrm{H}} S^{1 / 2} n_{\mathrm{H}}^{-3 / 2}=0,
\end{aligned}
$$

and we obtain $\left\{n_{\mathrm{G}}^{\mathrm{ii}}, n_{\mathrm{H}}{ }^{\mathrm{ii}}\right\}$ as follows:

$$
\begin{aligned}
& n_{\mathrm{G}}^{\mathrm{ii} *}(q)=\left(\frac{k_{\mathrm{G}}(1-q) \dot{M}}{2 b_{\mathrm{G}}}\right)^{2 / 3} S^{1 / 3}, \\
& n_{\mathrm{H}}^{\mathrm{ii} *}(q)=\left(\frac{k_{\mathrm{H}} q M}{2 b_{\mathrm{H}}}\right)^{2 / 3} S^{1 / 3} .
\end{aligned}
$$

From (3.2) and (3.3), we can confirm that the solution depends on $q$. As an example, we set parameters as $S=437 \mathrm{~km}^{2}, M=1,353 \times 10^{3}, b_{\mathrm{G}}=45 \times 10^{6}$ yen/year, $b_{\mathrm{H}}=79 \times 10^{6}$ yen/year, $k_{\mathrm{G}}=12,480 \mathrm{yen} /($ year $\cdot \mathrm{km}), k_{\mathrm{H}}=15,600$ yen $/$ (year $\left.\cdot \mathrm{km}\right)$. In all numerical examples described in the paper, we suppose Yokohama City in Japan. Detailed definitions of parameters are stated in Chapter 5. $\left\{n_{\mathrm{G}}^{\mathrm{ii} *}(q), n_{\mathrm{H}}^{\mathrm{ii}}(q)\right\}$ and the number of total stations are shown in Figure 1, and the following feature is obtained.

[feature 2]

When we assume the coexistence of gas and hydrogen stations, the maximum value of the optimal number of total stations is observed in the transition period.

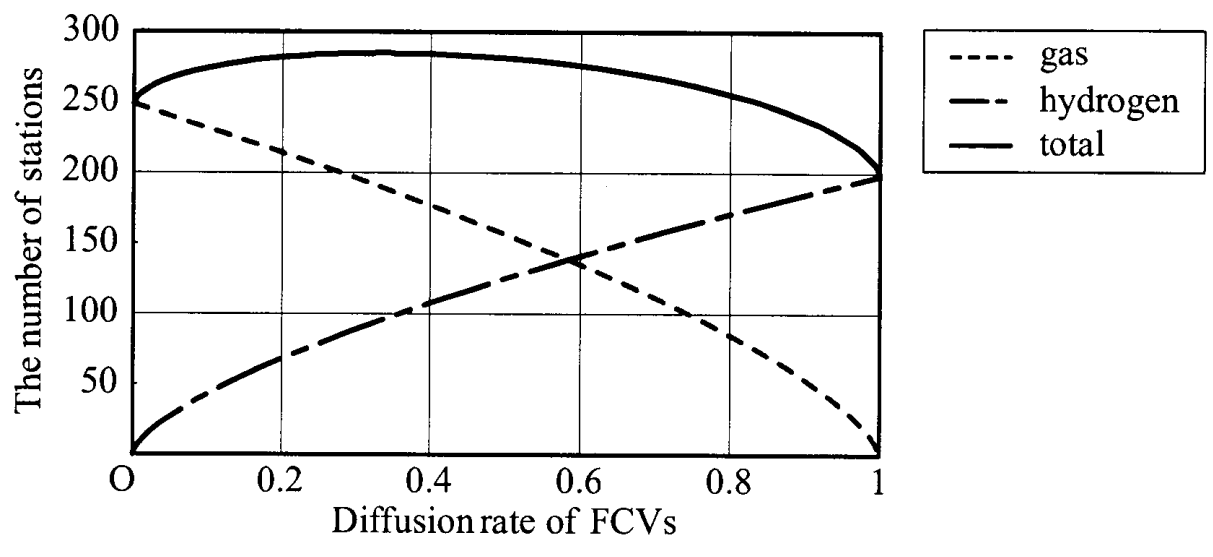

Figure 1: Optimal number of gas and hydrogen stations (no total constraint)

\subsection{Constraint of total station number}

As indicated above, we need more stations in the transition period than that before or after the transition. Is it natural for such a thing to occur in the real world? Probably, lots of people would says "No". Then, we should reconsider what we have to incorporate with.

First, to build stations, we need sites in the region. In lots of big cities however, there is not enough space. In such a case, new hydrogen stations are built by replacing gas stations that already exist. In addition, we usually need approval from the government when we intend to build public facilities such as hydrogen stations. The approval must be given with 
taking future demand into consideration, and can also be an element which obstructs the increase in the number of stations. All things stated above indicate that there is an upper limitation to the number of stations. Hence, we formulate the following problem, which adds one constraint to the previous one:

$$
\begin{array}{lll}
\text { [Problem ii } \left.{ }^{* *}\right] & \min . & T^{\mathrm{ii}}\left(n_{\mathrm{G}}, n_{\mathrm{H}}\right) \\
& \text { s.t. } & n_{\mathrm{G}}, n_{\mathrm{H}} \geq 0 \\
& n_{\mathrm{G}}(q)+n_{\mathrm{H}}(q) \leq N_{\text {high }},
\end{array}
$$

where

$$
N_{\text {high }}=\max \left[n_{\mathrm{G}}^{\mathrm{ii}^{*}}(0), n_{\mathrm{H}}^{\mathrm{ii} *}(1)\right] .
$$

Let us explain (3.4) and (3.5). Expressions $n_{\mathrm{G}}^{\mathrm{ii} *}(0)$ and $n_{\mathrm{H}}^{\mathrm{ii}}{ }^{*}(1)$ in (3.5) are both the optimal solutions in section 3.3-namely under no constraint. Since the numbers in parenthesis indicate the diffusion rate of FCVs, $N_{\text {high }}$ is the greater value of (i) optimal number of gas stations before transition, or (ii) optimal number of hydrogen stations after transition. It is reasonable that the upper limitations of the number of total stations would be $N_{\text {high }}$. Consequently, we appended the constraint (3.4) to the problem.

Since both the objective function and feasible region are convex, [Problem ii $\left.{ }^{* *}\right]$ is a convex programming problem. Then, the optimal solution $\left\{n_{\mathrm{G}}^{\mathrm{ii} * *}, n_{\mathrm{H}}^{\mathrm{ii} * *}\right\}$ can be solved by considering Karush-Kuhn-Tucker (KKT) conditions [18]. Lagrangian function of the problem is given by

$$
\begin{aligned}
L^{\mathrm{ii} * *}\left(n_{\mathrm{G}}, n_{\mathrm{H}} ; \lambda, \boldsymbol{\mu}\right)= & b_{\mathrm{G}} n_{\mathrm{G}}+b_{\mathrm{H}} n_{\mathrm{H}}+(1-q) M k_{\mathrm{G}} \sqrt{\frac{S}{n_{\mathrm{G}}}}+q M k_{\mathrm{H}} \sqrt{\frac{S}{n_{\mathrm{H}}}} \\
& +\lambda\left(n_{\mathrm{G}}+n_{\mathrm{H}}-N_{\mathrm{high}}\right)+\mu_{\mathrm{G}}\left(-n_{\mathrm{G}}\right)+\mu_{\mathrm{H}}\left(-n_{\mathrm{H}}\right)
\end{aligned}
$$

and KKT conditions are expressed as follows:

$$
\begin{aligned}
& \frac{\partial L^{\mathrm{ii}{ }^{* *}}}{\partial n_{\mathrm{G}}}=b_{\mathrm{G}}-\frac{1}{2}(1-q) M k_{\mathrm{G}} S^{1 / 2} n_{\mathrm{G}}^{-3 / 2}+\lambda-\mu_{\mathrm{G}}=0, \\
& \frac{\partial L^{\mathrm{ii} * *}}{\partial n_{\mathrm{H}}}=b_{\mathrm{H}}-\frac{1}{2} q M k_{\mathrm{H}} S^{1 / 2} n_{\mathrm{H}}^{-3 / 2}+\lambda-\mu_{\mathrm{H}}=0, \\
& \lambda, \mu_{\mathrm{G}}, \mu_{\mathrm{H}} \geq 0 \\
& \lambda\left(n_{\mathrm{G}}+n_{\mathrm{H}}-N_{\mathrm{high}}\right)=0, \\
& \mu_{\mathrm{G}}\left(-n_{\mathrm{G}}\right)=0 \\
& \mu_{\mathrm{H}}\left(-n_{\mathrm{H}}\right)=0
\end{aligned}
$$

where $\lambda$ denotes Lagrange multiplier for the total number constraint (3.4) and $\mu_{\mathrm{G}}, \mu_{\mathrm{H}}$ are those for nonnegativity constraints. From (3.1), $n_{\mathrm{G}}, n_{\mathrm{H}}>0$ is assured, then

$$
\mu_{\mathrm{G}}=\mu_{\mathrm{H}}=0 \text {. }
$$

Therefore, $\left\{n_{\mathrm{G}}^{\mathrm{ii}} * * n_{\mathrm{H}}^{\mathrm{ii} * *}\right\}$ is obtained in two cases, whether constraint (3.4) is active or not.

[Case a] Constraint (3.4) is non active $(\lambda=0)$

In this case, [Problem ii ${ }^{* *}$ is equal to [Problem $\mathrm{ii}^{*}$ ], so

$$
\left\{n_{\mathrm{G}}^{\mathrm{ii} * *}(q), n_{\mathrm{H}}^{\mathrm{ii} * *}(q)\right\}=\left\{n_{\mathrm{G}}^{\mathrm{ii} *}(q), n_{\mathrm{H}}^{\mathrm{ii} *}(q)\right\} .
$$


[Case b] Constraint (3.4) is active $(\lambda>0)$

On the other hand, if we assume that constraint (3.4) is active, then we get the following equation:

$$
n_{\mathrm{G}}+n_{\mathrm{H}}=N_{\text {high }}
$$

Furthermore, we also obtain

$$
-\lambda=b_{\mathrm{G}}-\frac{1}{2}(1-q) M k_{\mathrm{G}} S^{1 / 2} n_{\mathrm{G}}^{-3 / 2}=b_{\mathrm{H}}-\frac{1}{2} q M k_{\mathrm{H}} S^{1 / 2} n_{\mathrm{H}}^{-3 / 2}
$$

from (3.6), (3.7), and (3.8). By substituting (3.10) for (3.11), we get

$$
-\lambda=b_{\mathrm{G}}-\frac{1}{2}(1-q) M k_{\mathrm{G}} S^{1 / 2} n_{\mathrm{G}}^{-3 / 2}=b_{\mathrm{H}}-\frac{1}{2} q M k_{\mathrm{H}} S^{1 / 2}\left(N_{\text {high }}-n_{\mathrm{G}}\right)^{-3 / 2} .
$$

Now, the middle part of (3.12) is a monotonically increasing function of $n_{\mathrm{G}}$, which provides $-\infty$ when $n_{\mathrm{G}}=0$ and 0 when $n_{\mathrm{G}}=n_{\mathrm{G}}^{\mathrm{ii}}{ }^{*}(q)$. On the other hand, the right side of (3.12) is a monotonically decreasing function of $n_{\mathrm{G}}$, which provides 0 for $n_{\mathrm{G}}=N_{\text {high }}-n_{\mathrm{H}}^{\mathrm{ii}}(q)$ and $-\infty$ for $n_{\mathrm{G}}=N_{\text {high }}$. In addition, since $n_{\mathrm{G}}^{\mathrm{ii} *}(q)+n_{\mathrm{H}}^{\mathrm{ii} *}(q) \geq N_{\text {high }}$ is assumed in this case, the following inequality is obtained:

$$
N_{\text {high }}-n_{\mathrm{H}}^{\mathrm{ii} *}(q) \leq n_{\mathrm{G}}^{\mathrm{ii}^{*}}(q) .
$$

Therefore, (3.12) has a unique solution and $\lambda \geq 0$ is also assured. follows:

As a result of the preceding discussions, the optimal solution $\left\{n_{\mathrm{G}}^{\mathrm{ii} * *}, n_{\mathrm{H}}^{\mathrm{ii} * *}\right\}$ is derived as

a) when $N_{\text {high }} \geq n_{\mathrm{G}}^{\mathrm{ii}^{*}}(q)+n_{\mathrm{H}}^{\mathrm{ii} *}(q)$

$$
\left\{n_{\mathrm{G}}^{\mathrm{ii} * *}(q), n_{\mathrm{H}}^{\mathrm{ii} * *}(q)\right\}=\left\{n_{\mathrm{G}}^{\mathrm{ii} *}(q), n_{\mathrm{H}}^{\mathrm{ii} *}(q)\right\},
$$

b) when $N_{\text {high }} \leq n_{\mathrm{G}}^{\mathrm{ii} *}(q)+n_{\mathrm{H}}^{\mathrm{ii} *}(q)$

$$
\left\{\dot{n}_{\mathrm{G}}^{\mathrm{ii} * *}(q), n_{\mathrm{H}}^{\mathrm{ii} * *}(q)\right\}=\left\{x(q), N_{\mathrm{high}}-x(q)\right\},
$$

where $x(q)$ is the real value solution of

$$
b_{\mathrm{G}}-\frac{1}{2}(1-q) M k_{\mathrm{G}} S^{1 / 2} x^{-3 / 2}=b_{\mathrm{H}}-\frac{1}{2} q M k_{\mathrm{H}} S^{1 / 2}\left(N_{\mathrm{high}}-x\right)^{-3 / 2} .
$$

$\left\{n_{\mathrm{G}}^{\mathrm{ii} * *}(q), n_{\mathrm{H}}^{\mathrm{ii} * *}(q)\right\}$ and the number of total stations are demonstrated in Figure 2, where $S=437 \mathrm{~km}^{2}, M=1,353 \times 10^{3}, b_{\mathrm{G}}=45 \times 10^{6}$ yen $/$ year, $b_{\mathrm{H}}=79 \times 10^{6}$ yen $/$ year, $k_{\mathrm{G}}=12,480$ yen $/($ year $\cdot \mathrm{km}), k_{\mathrm{H}}=15,600$ yen $/$ (year $\cdot \mathrm{km}$ ). From Figure 2, we can confirm that the number of total stations is constant for a long time.

\section{Incorporating Hybrid Stations}

In the preceding section, we discussed the optimal number of stations assuming that only gas and hydrogen stations exist. However, in scenarios described by The Agency for Natural Resources and Energy, hydrogen refueling facilities are located with existing gas stations in early period. Hence, in this section we consider not only gas and hydrogen stations, but hybrid stations which are refueling facilities for both gasoline vehicles and FCVs. 

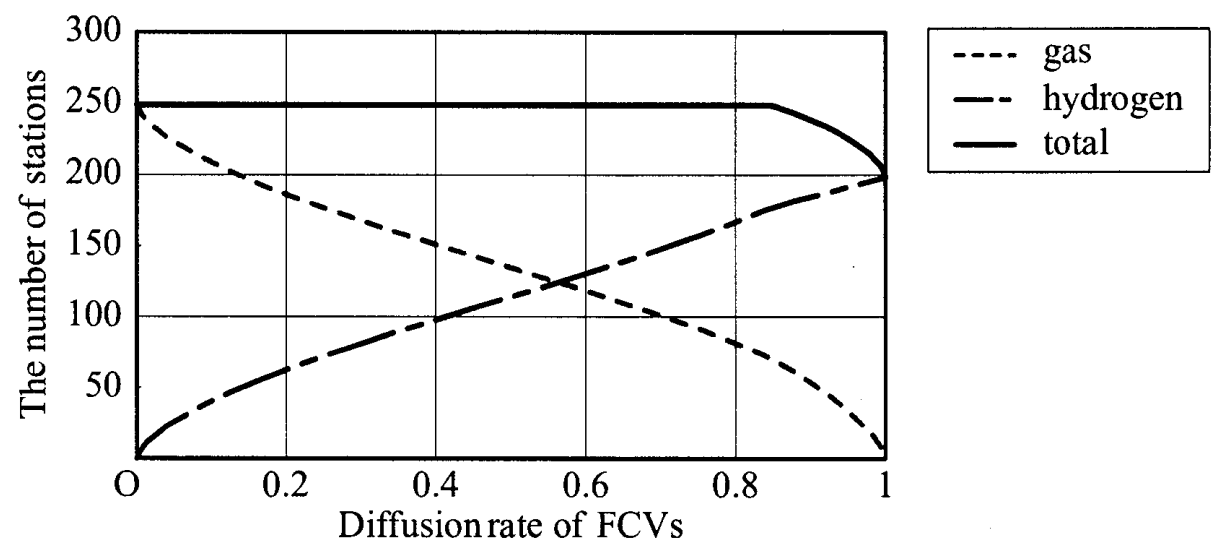

Figure 2: Optimal number of gas and hydrogen stations (with total constraint)

\subsection{Assumptions}

Suppose a region whose size is $S$, and that there are $(1-q) M$ gasoline vehicles and $q M$ FCVs in the region ( $q$ denotes the diffusion rate of FCVs and $0 \leq q \leq 1$ ). For simplicity, we assume that $q$ does not depend on a position in the region, and that gasoline vehicles and FCVs are uniformly distributed respectively.

Let us consider building gas, hydrogen, and hybrid stations simultaneously as refueling facilities. The numbers of stations are defined as $n_{\mathrm{G}}, n_{\mathrm{H}}$, and $n_{\mathrm{I}}$ respectively, where subscript I denotes hybrid. All gasoline vehicles are assumed to refuel at the nearest gas or hybrid stations, and FCVs hybrid or hydrogen stations. That is to say, gasoline vehicles can use $n_{\mathrm{G}}+n_{\mathrm{I}}$ stations and FCVs $n_{\mathrm{I}}+n_{\mathrm{H}}$. Accordingly, in the similar arguments of previous sections, the size of catchment area for gasoline vehicles is calculated $S /\left(n_{\mathrm{G}}+n_{\mathrm{I}}\right)$ and $S /\left(n_{\mathrm{I}}+n_{\mathrm{H}}\right)$ for FCVs.

\subsection{Cost definition}

Now we define operation cost of stations and transportation cost of vehicles in this case. First, we consider the operation cost of stations in the region. In this section, we simply assume that one gas station costs $b_{\mathrm{G}}\left[\right.$ yen/(year)], hybrid stations $b_{\mathrm{I}}[$ yen/(year)], and hydrogen stations $b_{\mathrm{H}}[$ yen/(year)]. Furthermore, we also assume two inequalities below. Firstly, it is natural that operation cost increases as the function of facilities becomes complicated. This implies the following inequality:

$$
b_{\mathrm{G}}, b_{\mathrm{H}}<b_{\mathrm{I}} \text {. }
$$

Secondly, managing one hybrid station should be more effective than managing a gas and a hydrogen station respectively; that is

$$
b_{\mathrm{G}}+b_{\mathrm{H}}>b_{\mathrm{I}}
$$

As previously mentioned, there are $n_{\mathrm{G}}$ gas stations, $n_{\mathrm{I}}$ hybrid stations, and $n_{\mathrm{H}}$ hydrogen stations in the region. Hence, total operation cost of stations $f^{\mathrm{iii}}\left(n_{\mathrm{G}}, n_{\mathrm{I}}, n_{\mathrm{H}}\right)$ is given by

$$
f^{\mathrm{iii}}\left(n_{\mathrm{G}}, n_{\mathrm{I}}, n_{\mathrm{H}}\right)=b_{\mathrm{G}} n_{\mathrm{G}}+b_{\mathrm{I}} n_{\mathrm{I}}+b_{\mathrm{H}} n_{\mathrm{H}} .
$$

Next, we address transportation cost of vehicles. In a similar manner, we calculate based on the average distance. We should take into consideration the difference between the average distance of gasoline vehicles and that of FCVs. First, the size of the station's 
catchment area for gasoline vehicles is given by $S /\left(n_{\mathrm{G}}+n_{\mathrm{I}}\right)$, so the scale is $\sqrt{S /\left(n_{\mathrm{G}}+n_{\mathrm{I}}\right)}$. While, the size of the station's catchment area for FCVs is given by $S /\left(n_{\mathrm{I}}+n_{\mathrm{H}}\right)$, so its scale is $\sqrt{S /\left(n_{\mathrm{I}}+n_{\mathrm{H}}\right)}$. Consequently, the average distance for gasoline vehicles $\bar{d}_{\mathrm{G}}^{\mathrm{iii}}\left(n_{\mathrm{G}}, n_{\mathrm{I}}\right)[\mathrm{km}]$ is obtained as

$$
\bar{d}_{\mathrm{G}}^{\mathrm{iii}}\left(n_{\mathrm{G}}, n_{\mathrm{I}}\right)=\kappa \sqrt{S /\left(n_{\mathrm{G}}+n_{\mathrm{I}}\right)}
$$

and that for FCVs $\bar{d}_{\mathrm{H}}^{\mathrm{iii}}\left(n_{\mathrm{I}}, n_{\mathrm{H}}\right)[\mathrm{km}]$

$$
\bar{d}_{\mathrm{H}}^{\mathrm{iii}}\left(n_{\mathrm{I}}, n_{\mathrm{H}}\right)=\kappa \sqrt{S /\left(n_{\mathrm{I}}+n_{\mathrm{H}}\right)} .
$$

Therefore, average transportation cost per one gasoline vehicle can be written as $k_{\mathrm{G}} \bar{d}_{\mathrm{G}}^{\overline{i i i}}\left(n_{\mathrm{G}}, n_{\mathrm{I}}\right)$ and FCVs $k_{\mathrm{H}} \bar{d}_{\mathrm{H}}^{\mathrm{iii}}\left(n_{\mathrm{I}}, n_{\mathrm{H}}\right)$, where $k_{\mathrm{G}}$ and $k_{\mathrm{H}}$ have already been defined in the previous section. Then, by multiplying the number of vehicles and the average distances, we obtain the total transportation cost $g^{\mathrm{iii}}\left(n_{\mathrm{G}}, n_{\mathrm{I}}, n_{\mathrm{H}}\right)$ as follows:

$$
g^{\mathrm{iii}}\left(n_{\mathrm{G}}, n_{\mathrm{I}}, n_{\mathrm{H}}\right)=k_{\mathrm{G}}(1-q) M \sqrt{S /\left(n_{\mathrm{G}}+n_{\mathrm{I}}\right)}+k_{\mathrm{H}} q M \sqrt{S /\left(n_{\mathrm{I}}+n_{\mathrm{H}}\right)} .
$$

\subsection{Total cost minimization}

Let us define the total cost $T^{\mathrm{iii}}\left(n_{\mathrm{G}}, n_{\mathrm{I}}, n_{\mathrm{H}}\right)$ as a sum of $f^{\mathrm{iii}}\left(n_{\mathrm{G}}, n_{\mathrm{I}}, n_{\mathrm{H}}\right)$ and $g^{\mathrm{iii}}\left(n_{\mathrm{G}}, n_{\mathrm{I}}, n_{\mathrm{H}}\right)$ :

$$
T^{\mathrm{iii}}\left(n_{\mathrm{G}}, n_{\mathrm{I}}, n_{\mathrm{H}}\right)=f^{\mathrm{iii}}\left(n_{\mathrm{G}}, n_{\mathrm{I}}, n_{\mathrm{H}}\right)+g^{\mathrm{iii}}\left(n_{\mathrm{G}}, n_{\mathrm{I}}, n_{\mathrm{H}}\right) .
$$

The objective of the present section is to find the optimal solution $\left\{n_{\mathrm{G}}^{\mathrm{iii} *}, n_{\mathrm{I}}^{\mathrm{iii} *}, n_{\mathrm{H}}^{\mathrm{iii}}\right\}$ which minimizes the total cost $T^{\mathrm{iii}}\left(n_{\mathrm{G}}, n_{\mathrm{I}}, n_{\mathrm{H}}\right)$. For convenience, we assume that $n_{\mathrm{G}}, n_{\mathrm{I}}$, and $n_{\mathrm{H}}$ are real numbers.

Now, let us consider the following mathematical programming problem:

$$
\begin{array}{lll}
\text { [Problem iii* } & \min . & T^{\mathrm{iii}}\left(n_{\mathrm{G}}, n_{\mathrm{I}}, n_{\mathrm{H}}\right) \\
\text { s.t. } & n_{\mathrm{G}} \geq 0 \\
& n_{\mathrm{I}} \geq 0 \\
& n_{\mathrm{H}} \geq 0 .
\end{array}
$$

We know that $T^{\mathrm{iii}}\left(n_{\mathrm{G}}, n_{\mathrm{I}}, n_{\mathrm{H}}\right)$ is a convex function when $n_{\mathrm{G}}+n_{\mathrm{I}}, n_{\mathrm{I}}+n_{\mathrm{H}}>0$ (see Appendix B). Furthermore, about $T^{\mathrm{iii}}\left(n_{\mathrm{G}}, n_{\mathrm{I}}, n_{\mathrm{H}}\right)$, we have

$$
\left.\begin{array}{rl}
\lim _{n_{\mathrm{G}} \rightarrow+\infty} T^{\mathrm{iii}}\left(n_{\mathrm{G}}, n_{\mathrm{I}}, n_{\mathrm{H}}\right) & =+\infty ; \\
\lim _{n_{\mathrm{I}} \rightarrow+\infty} T^{\mathrm{iii}}\left(n_{\mathrm{G}}, n_{\mathrm{I}}, n_{\mathrm{H}}\right) & =+\infty ; \\
\lim _{n_{\mathrm{H}} \rightarrow+\infty} T^{\mathrm{iii}}\left(n_{\mathrm{G}}, n_{\mathrm{I}}, n_{\mathrm{H}}\right) & =+\infty ; \\
\lim _{\rightarrow+0, n_{\mathrm{I}} \rightarrow+0} T^{\mathrm{iii}}\left(n_{\mathrm{G}}, n_{\mathrm{I}}, n_{\mathrm{H}}\right) & =+\infty ; \\
\lim _{\rightarrow+0, n_{\mathrm{H}} \rightarrow+0} T^{\mathrm{iii}}\left(n_{\mathrm{G}}, n_{\mathrm{I}}, n_{\mathrm{H}}\right) & =+\infty ;
\end{array}\right\}
$$

Accordingly, we derive the optimal solution $\left\{n_{\mathrm{G}}^{\mathrm{iii} *}, n_{\mathrm{I}}^{\mathrm{iii}}, n_{\mathrm{H}}^{\mathrm{iii}}\right\}$ by solving KKT conditions.

Lagrangian function for this optimization problem is given by

$$
L^{\mathrm{iii}{ }^{*}}\left(n_{\mathrm{G}}, n_{\mathrm{I}}, n_{\mathrm{H}} ; \boldsymbol{\mu}\right)=T^{\mathrm{iii}}\left(n_{\mathrm{G}}, n_{\mathrm{I}}, n_{\mathrm{H}}\right)+\mu_{\mathrm{G}}\left(-n_{\mathrm{G}}\right)+\mu_{\mathrm{I}}\left(-n_{\mathrm{I}}\right)+\mu_{\mathrm{H}}\left(-n_{\mathrm{H}}\right)
$$


and KKT conditions are as follows:

$$
\begin{aligned}
& \frac{\partial L^{\mathrm{iii}^{*}}}{\partial n_{\mathrm{G}}}=b_{\mathrm{G}}-\frac{1}{2}(1-q) M k_{\mathrm{G}} S^{1 / 2}\left(n_{\mathrm{G}}+n_{\mathrm{I}}\right)^{-3 / 2}-\mu_{\mathrm{G}}=0, \\
& \frac{\partial L^{\mathrm{iii}^{*}}}{\partial n_{\mathrm{I}}}=b_{\mathrm{I}}-\frac{1}{2}(1-q) M k_{\mathrm{G}} S^{1 / 2}\left(n_{\mathrm{G}}+n_{\mathrm{I}}\right)^{-3 / 2} \\
& -\frac{1}{2} q M k_{\mathrm{H}} S^{1 / 2}\left(n_{\mathrm{I}}+n_{\mathrm{H}}\right)^{-3 / 2}-\mu_{\mathrm{I}}=0, \\
& \frac{\partial L^{\mathrm{iii}^{*}}}{\partial n_{\mathrm{H}}}=b_{\mathrm{H}}-\frac{1}{2} q M k_{\mathrm{H}} S^{1 / 2}\left(n_{\mathrm{I}}+n_{\mathrm{H}}\right)^{-3 / 2}-\mu_{\mathrm{H}}=0, \\
& \mu_{\mathrm{G}}, \mu_{\mathrm{I}}, \mu_{\mathrm{H}} \geq 0 \\
& \mu_{\mathrm{G}}\left(-n_{\mathrm{G}}\right)=0 \text {, } \\
& \mu_{\mathrm{I}}\left(-n_{\mathrm{I}}\right)=0 \text {, } \\
& \mu_{\mathrm{H}}\left(-n_{\mathrm{H}}\right)=0 \text {, }
\end{aligned}
$$

where $\mu_{\mathrm{G}}, \mu_{\mathrm{I}}, \mu_{\mathrm{H}}$ are Lagrange multipliers for nonnegativity constraints.

To solve these KKT conditions we have to consider $2^{3}$ cases, because we have 3 constraints (4.2), (4.3), and (4.4). More precisely, we incorporate whether each constraint is active or not (to say $\mu=0$ or not). Firstly, when all constraints (4.2), (4.3), and (4.4) are active, $T^{\mathrm{iii}}\left(n_{\mathrm{G}}, n_{\mathrm{I}}, n_{\mathrm{H}}\right) \rightarrow+\infty$ because of $n_{\mathrm{G}}=n_{\mathrm{I}}=n_{\mathrm{H}}=0$. Similarly, when (4.2) and (4.3) are active constraints, or when (4.3) and (4.4) are active, $T^{\mathrm{iii}}\left(n_{\mathrm{G}}, n_{\mathrm{I}}, n_{\mathrm{H}}\right)$ also becomes $+\infty$. On the other hand, when no constraint is active, $b_{\mathrm{G}}+b_{\mathrm{H}}=b_{\mathrm{I}}$ is supposed by $\mu_{\mathrm{G}}=\mu_{\mathrm{I}}=\mu_{\mathrm{H}}=0,(4.5),(4.6)$ and (4.7). This fact contradicts (4.1). Finally, when only (4.3) is an active constraint, $b_{\mathrm{I}}-b_{\mathrm{G}}-b_{\mathrm{H}}=\mu_{\mathrm{I}}>0$ is obtained by $\mu_{\mathrm{G}}=\mu_{\mathrm{H}}=0,(4.5),(4.6)$, and (4.7). This is also a contradiction to (4.1). As a consequence as expressed above, the optimal solution $\left\{n_{\mathrm{G}}^{\mathrm{iii} *}, n_{\mathrm{I}}^{\mathrm{iii} *}, n_{\mathrm{H}}^{\mathrm{iii*}}\right\}$ is obtained in the following three cases.

\section{[Case a] Constraint (4.4) is active [Former Period]}

In this case, we have

$$
n_{\mathrm{H}}^{\mathrm{iii} *}(q)=0 .
$$

In addition, from (4.5) and $\mu_{\mathrm{G}}=0$, we get

$$
n_{\mathrm{G}}+n_{\mathrm{I}}=\left(\frac{k_{\mathrm{G}}(1-q) M}{2 b_{\mathrm{G}}}\right)^{2 / 3} S^{1 / 3}
$$

Furthermore, by substituting the equations above and $\mu_{\mathrm{I}}=0$ for (4.6), we get

$$
n_{\mathrm{I}}^{\mathrm{iii} *}(q)=\left(\frac{k_{\mathrm{H}} q M}{2\left(b_{\mathrm{I}}-b_{\mathrm{G}}\right)}\right)^{2 / 3} S^{1 / 3} .
$$

Hence, from (4.8) and (4.9), we derive

$$
n_{\mathrm{G}}^{\mathrm{iii} *}(q)=\left\{\left(\frac{k_{\mathrm{G}}(1-q) M}{2 b_{\mathrm{G}}}\right)^{2 / 3}-\left(\frac{k_{\mathrm{H}} q M}{2\left(b_{\mathrm{I}}-b_{\mathrm{G}}\right)}\right)^{2 / 3}\right\} S^{1 / 3} .
$$

$n_{\mathrm{G}}^{\mathrm{iii}}{ }^{*}(q)$ is supposed to be greater than 0 , then

$$
q \leq \frac{\left(b_{\mathrm{I}}-b_{\mathrm{G}}\right) k_{\mathrm{G}}}{b_{\mathrm{G}} k_{\mathrm{H}}+\left(b_{\mathrm{I}}-b_{\mathrm{G}}\right) k_{\mathrm{G}}}
$$


is obtained as the condition of $q$. In this case, KKT conditions are satisfied because

$$
\mu_{\mathrm{H}}=\left(b_{\mathrm{G}}+b_{\mathrm{H}}\right)-b_{\mathrm{I}}>0
$$

is led from (4.7).

\section{[Case b] Constraints (4.2) and (4.4) are active [Middle Period]}

In this case, we have

$$
\begin{gathered}
n_{\mathrm{G}}^{\mathrm{iii*}}(q)=0 \\
n_{\mathrm{H}}^{\mathrm{iii} *}(q)=0
\end{gathered}
$$

Thus, from (4.6) and $\mu_{\mathrm{I}}=0$, we get

$$
n_{\mathrm{I}}^{\mathrm{iii}^{*}}(q)=\left(\frac{k_{\mathrm{G}}(1-q) M+k_{\mathrm{H}} q M}{2 b_{\mathrm{I}}}\right)^{2 / 3} S^{1 / 3} .
$$

To satisfy KKT conditions, $\mu_{\mathrm{G}}, \mu_{\mathrm{H}} \geq 0$ are essential. Therefore, by substituting (4.10) for (4.5) and (4.7), we get the following inequality as the condition of $q$ :

$$
\frac{\left(b_{\mathrm{I}}-b_{\mathrm{G}}\right) k_{\mathrm{G}}}{b_{\mathrm{G}} k_{\mathrm{H}}+\left(b_{\mathrm{I}}-b_{\mathrm{G}}\right) k_{\mathrm{G}}} \leq q \leq \frac{b_{\mathrm{H}} k_{\mathrm{G}}}{\left(b_{\mathrm{I}}-b_{\mathrm{H}}\right) k_{\mathrm{H}}+b_{\mathrm{H}} k_{\mathrm{G}}} \text {. }
$$

\section{[Case c] Constraint (4.2) is active [Latter period]}

In this case, we have

$$
n_{\mathrm{G}}^{\mathrm{iii} *}(q)=0 .
$$

Furthermore, from (4.7) and $\mu_{\mathrm{H}}=0$, we get

$$
n_{\mathrm{I}}^{\mathrm{iii}^{*}}(q)+n_{\mathrm{H}}^{\mathrm{iii} *}(q)=\left(\frac{k_{\mathrm{H}} q M}{2 b_{\mathrm{H}}}\right)^{2 / 3} S^{1 / 3} .
$$

Now, by substituting the preceding equations and $\mu_{\mathrm{I}}=0$ for $(4.6)$, we get

$$
n_{\mathrm{I}}^{\mathrm{iii} *}(q)=\left(\frac{k_{\mathrm{G}}(1-q) M}{2\left(b_{\mathrm{I}}-b_{\mathrm{H}}\right)}\right)^{2 / 3} S^{1 / 3} .
$$

Hence, from (4.11) and (4.12), we derive

$$
n_{\mathrm{H}}^{\mathrm{iii}}{ }^{*}(q)=\left\{\left(\frac{k_{\mathrm{H}} q M}{2 b_{\mathrm{H}}}\right)^{2 / 3}-\left(\frac{k_{\mathrm{G}}(1-q) M}{2\left(b_{\mathrm{I}}-b_{\mathrm{H}}\right)}\right)^{2 / 3}\right\} S^{1 / 3} .
$$

$n_{\mathrm{H}}^{\mathrm{iii}}(q)>0$ is supposed, and

$$
q \geq \frac{b_{\mathrm{H}} k_{\mathrm{G}}}{\left(b_{\mathrm{I}}-b_{\mathrm{H}}\right) k_{\mathrm{H}}+b_{\mathrm{H}} k_{\mathrm{G}}}
$$

is required as a condition of $q$. In present case, KKT conditions are all satisfied because

$$
\mu_{\mathrm{G}}=\left(b_{\mathrm{G}}+b_{\mathrm{H}}\right)-b_{\mathrm{I}}>0
$$

is obtained from (4.5).

$\left\{n_{\mathrm{G}}^{\mathrm{iii} *}(q), n_{\mathrm{I}}^{\mathrm{iii} *}(q), n_{\mathrm{H}}^{\mathrm{iii} *}(q)\right\}$ and the number of total stations in various $q$ are demonstrated in Figure 3, where parameters are $S=437 \mathrm{~km}^{2}, M=1,353 \times 10^{3}, b_{\mathrm{G}}=45 \times 10^{6}$ yen $/$ year, $b_{\mathrm{I}}=79 \times 10^{6}$ yen $/$ year, $b_{\mathrm{H}}=109 \times 10^{6}$ yen $/$ year, $k_{\mathrm{G}}=12,480$ yen $/($ year $\cdot \mathrm{km})$, $k_{\mathrm{H}}=15,600$ yen $/($ year $\cdot \mathrm{km}$ ). From Figure 3, we can obtain the following features: 
[feature 3]

If three types of stations namely gas, hybrid, and hydrogen stations are assumed, then the optimal number of total stations in transition period is less than that before or after transition.

[feature 4]

If three types of stations namely gas, hybrid, and hydrogen stations are assumed, then all stations in the region should be hybrid stations in the middle period of transition.

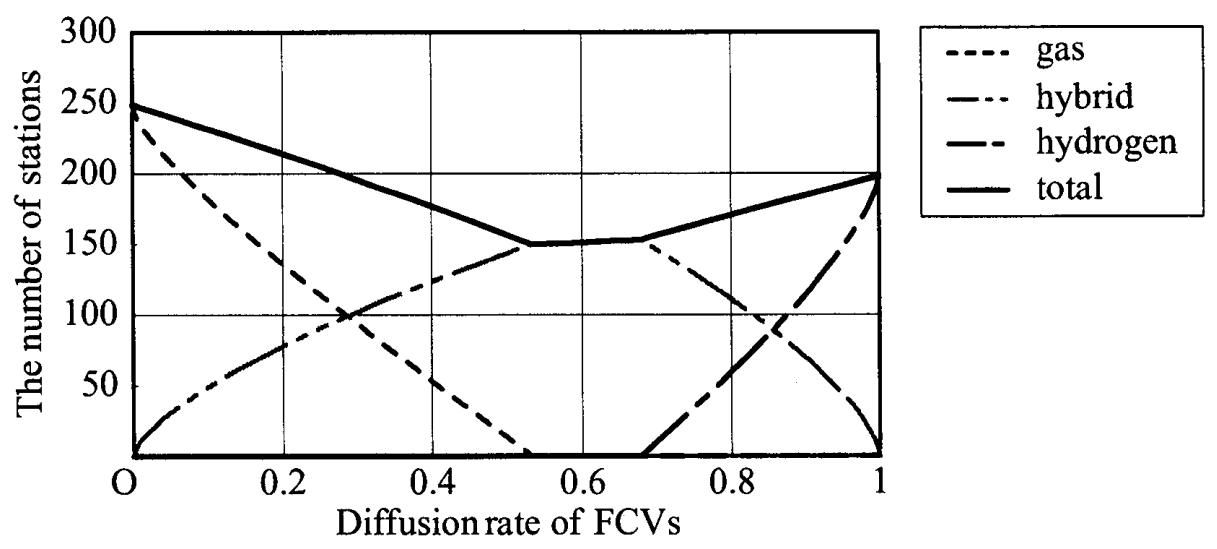

Figure 3: Optimal number of gas, hybrid and hydrogen stations (no total constraint)

\subsection{Constraint of total station number}

In Section 4.3, we calculated the optimal number of stations under the assumption of three types - gas, hybrid, and hydrogen - stations. As a result, we clarified that fewer stations are needed in the transition period. This feature is completely opposite to Section 3. In the preceding section, we neglected some factors such as location site and governmental approval. Then, we should any factors that we neglected previously in this section.

Decreasing the number of total stations means that some stations are removed. It is probable that the stations which are removed will not retain their equipment and their sites will be sold at worst. Station managers must want to avoid such things if the stations are to be used in the future.

What we stated above indicates that there is a lower limitation of the number of total stations. Accordingly, we formulate the following mathematical programming problem, which adds a constraint to [Problem iii*].

$$
\begin{array}{cll}
\text { [Problem iii* } & \text { min. } & T^{\mathrm{iii}}\left(n_{\mathrm{G}}, n_{\mathrm{I}}, n_{\mathrm{H}}\right) \\
\text { s.t. } & n_{\mathrm{G}} \geq 0 \\
& n_{\mathrm{I}} \geq 0 \\
& n_{\mathrm{H}} \geq 0 \\
& n_{\mathrm{G}}(q)+n_{\mathrm{I}}(q)+n_{\mathrm{H}}(q) \geq N_{\text {low }}
\end{array}
$$

where

$$
N_{\mathrm{low}}=\min \left[n_{\mathrm{G}}^{\mathrm{iii}^{*}}(0), n_{\mathrm{H}}^{\mathrm{iii} *}(1)\right]
$$


Let us explain (4.16) and (4.17). Both $n_{\mathrm{G}}^{\mathrm{iii} *}(0)$ and $n_{\mathrm{H}}^{\mathrm{iii}}(1)$ in (4.17) are optimal solutions in Section 4.3, which does not consider the constraint of the number of total stations. Here, values in parentheses indicate the diffusion rate of FCVs, and $N_{\text {low }}$ is the lesser value of (i) the optimal number of total stations before transition or (ii) after transition. It is reasonable that the lower limitations of the number of total stations would be $N_{\text {low }}$. Consequently, we append a constraint (4.16) to [Problem iii**].

[Problem iii**] is a convex programming problem because both objective function and feasible region are convex. Hence, $\left\{n_{\mathrm{G}}^{\mathrm{iii**}}, n_{\mathrm{I}}^{\mathrm{iii**}}, n_{\mathrm{H}}^{\mathrm{iii} * *}\right\}$ which satisfies the KKT conditions gives the optimal solution. Lagrangian function of the problem is given by

$$
\begin{aligned}
L^{\mathrm{iii**}}\left(n_{\mathrm{G}}, n_{\mathrm{I}}, n_{\mathrm{H}} ; \lambda, \boldsymbol{\mu}\right)=T^{\mathrm{iii}}\left(n_{\mathrm{G}}, n_{\mathrm{I}}, n_{\mathrm{H}}\right)+\lambda\left(N_{\text {low }}-n_{\mathrm{G}}-n_{\mathrm{I}}-n_{\mathrm{H}}\right) \\
+\mu_{\mathrm{G}}\left(-n_{\mathrm{G}}\right)+\mu_{\mathrm{I}}\left(-n_{\mathrm{I}}\right)+\mu_{\mathrm{H}}\left(-n_{\mathrm{H}}\right)
\end{aligned}
$$

and KKT conditions are expressed as follows:

$$
\begin{aligned}
& \frac{\partial L^{\mathrm{ii}{ }^{* *}}}{\partial n_{\mathrm{G}}}=b_{\mathrm{G}}-\frac{1}{2}(1-q) M k_{\mathrm{G}} S^{1 / 2}\left(n_{\mathrm{G}}+n_{\mathrm{I}}\right)^{-3 / 2}-\lambda-\mu_{\mathrm{G}}=0, \\
& \frac{\partial L^{\mathrm{iii**}}}{\partial n_{\mathrm{I}}}=b_{\mathrm{I}}-\frac{1}{2}(1-q) M k_{\mathrm{G}} S^{1 / 2}\left(n_{\mathrm{G}}+n_{\mathrm{I}}\right)^{-3 / 2} \\
& -\frac{1}{2} q M k_{\mathrm{H}} S^{1 / 2}\left(n_{\mathrm{I}}+n_{\mathrm{H}}\right)^{-3 / 2}-\lambda-\mu_{\mathrm{I}}=0, \\
& \frac{\partial L^{\mathrm{iii} * *}}{\partial n_{\mathrm{H}}}=b_{\mathrm{H}}-\frac{1}{2} q M k_{\mathrm{H}} S^{1 / 2}\left(n_{\mathrm{I}}+n_{\mathrm{H}}\right)^{-3 / 2}-\lambda-\mu_{\mathrm{H}}=0, \\
& \lambda, \mu_{\mathrm{G}}, \mu_{\mathrm{I}}, \mu_{\mathrm{H}} \geq 0 \\
& \lambda\left(N_{\text {low }}-n_{\mathrm{G}}-n_{\mathrm{I}}-n_{\mathrm{H}}\right)=0, \\
& \mu_{\mathrm{G}}\left(-n_{\mathrm{G}}\right)=0 \text {, } \\
& \mu_{\mathrm{I}}\left(-n_{\mathrm{I}}\right)=0 \\
& \mu_{\mathrm{H}}\left(-n_{\mathrm{H}}\right)=0 \text {. }
\end{aligned}
$$

where $\lambda$ denotes Lagrange multiplier for the total number constraint (4.16) and $\mu_{\mathrm{G}}, \mu_{\mathrm{I}}, \mu_{\mathrm{H}}$ are those for nonnegativity constraints.

To obtain the optimal solution $\left\{n_{\mathrm{G}}^{\mathrm{iii} * *}(q), n_{\mathrm{I}}^{\mathrm{iii} * *}(q), n_{\mathrm{H}}^{\mathrm{iii**}}(q)\right\}$, we have to consider two cases, namely whether constraint (4.16) is active or not.

[Case a] Constraint (4.16) is non active $(\lambda=0)$

In this case, [Problem iii**] is equivalent to [Problem iii*], then

$$
\left\{n_{\mathrm{G}}^{\mathrm{iii}^{* *}}(q), n_{\mathrm{I}}^{\mathrm{iii**}}(q), n_{\mathrm{H}}^{\mathrm{iii} * *}(q)\right\}=\left\{n_{\mathrm{G}}^{\mathrm{iii} *}(q), n_{\mathrm{I}}^{\mathrm{iii}^{*}}(q), n_{\mathrm{H}}^{\mathrm{iii}^{*}}(q)\right\}
$$

is obtained.

[Case b] Constraint (4.16) is active $(\lambda>0)$

In this case,

$$
n_{\mathrm{G}}+n_{\mathrm{I}}+n_{\mathrm{H}}=N_{\mathrm{low}}
$$

is assumed. Although it is complicated to derive (see Appendix C), the optimal solution is given as follows: 
b-1) when $q \leq 1-\frac{2 N_{\text {low }}^{3 / 2}\left(b_{\mathrm{I}}-b_{\mathrm{H}}\right)}{M S^{1 / 2} k_{\mathrm{G}}}$, and $q \leq \frac{2 N_{\text {low }}^{3 / 2}\left(b_{\mathrm{I}}-b_{\mathrm{G}}\right)}{M S^{1 / 2} k_{\mathrm{H}}}$

$$
\begin{aligned}
& n_{\mathrm{G}}^{\mathrm{iii} * *}(q)=N_{\text {low }}-\left(\frac{k_{\mathrm{H}} q M}{2\left(b_{\mathrm{I}}-b_{\mathrm{G}}\right)}\right)^{2 / 3} S^{1 / 3}, \\
& n_{\mathrm{I}}^{\mathrm{iii} * *}(q)=\left(\frac{k_{\mathrm{H}} q M}{2\left(b_{\mathrm{I}}-b_{\mathrm{G}}\right)}\right)^{2 / 3} S^{1 / 3}, \\
& n_{\mathrm{H}}^{\mathrm{iii} * *}(q)=0 .
\end{aligned}
$$

b-2) when $1-\frac{2 N_{\text {low }}^{3 / 2}\left(b_{\mathrm{I}}-b_{\mathrm{H}}\right)}{M S^{1 / 2} k_{\mathrm{G}}} \leq q \leq \frac{2 N_{\text {low }}^{3 / 2}\left(b_{\mathrm{I}}-b_{\mathrm{G}}\right)}{M S^{1 / 2} k_{\mathrm{H}}}$

$$
\begin{aligned}
& n_{\mathrm{G}}^{\mathrm{iii} * *}(q)=N_{\text {low }}-\left(\frac{k_{\mathrm{H}} q M}{2\left(b_{\mathrm{I}}-b_{\mathrm{G}}\right)}\right)^{2 / 3} S^{1 / 3} \\
& n_{\mathrm{I}}^{\mathrm{iii} * *}(q)=\left\{\left(\frac{k_{\mathrm{H}} q M}{2\left(b_{\mathrm{I}}-b_{\mathrm{G}}\right)}\right)^{2 / 3}+\left(\frac{k_{\mathrm{G}}(1-q) M}{2\left(b_{\mathrm{I}}-b_{\mathrm{H}}\right)}\right)^{2 / 3}\right\} S^{1 / 3}-N_{\mathrm{low}} \\
& n_{\mathrm{H}}^{\mathrm{iii**}}(q)=N_{\text {low }}-\left(\frac{k_{\mathrm{G}}(1-q) M}{2\left(b_{\mathrm{I}}-b_{\mathrm{H}}\right)}\right)^{2 / 3} S^{1 / 3}
\end{aligned}
$$

b-3) when $\frac{2 N_{\text {low }}^{3 / 2}\left(b_{\mathrm{I}}-b_{\mathrm{G}}\right)}{M S^{1 / 2} k_{\mathrm{H}}} \leq q \leq 1-\frac{2 N_{\mathrm{low}}^{3 / 2}\left(b_{\mathrm{I}}-b_{\mathrm{H}}\right)}{M S^{1 / 2} k_{\mathrm{G}}}$

$$
\begin{aligned}
& n_{\mathrm{G}}^{\mathrm{iii**}}(q)=0, \\
& n_{\mathrm{I}}^{\mathrm{iii}^{* *}}(q)=N_{\text {low }}, \\
& n_{\mathrm{H}}^{\mathrm{iii**}}(q)=0 .
\end{aligned}
$$

b-4) when $\frac{2 N_{\text {low }}^{3 / 2}\left(b_{\mathrm{I}}-b_{\mathrm{G}}\right)}{M S^{1 / 2} k_{\mathrm{H}}}<q$, and $1-\frac{2 N_{\text {low }}^{3 / 2}\left(b_{\mathrm{I}}-b_{\mathrm{H}}\right)}{M S^{1 / 2} k_{\mathrm{G}}}<q$

$$
\begin{aligned}
& n_{\mathrm{G}}^{\mathrm{iii**}}(q)=0, \\
& n_{\mathrm{I}}^{\mathrm{iii} * *}(q)=\left(\frac{k_{\mathrm{G}}(1-q) M}{2\left(b_{\mathrm{I}}-b_{\mathrm{H}}\right)}\right)^{2 / 3} S^{1 / 3}, \\
& n_{\mathrm{H}}^{\mathrm{iij**}}(q)=N_{\text {low }}-\left(\frac{k_{\mathrm{G}}(1-q) M}{2\left(b_{\mathrm{I}}-b_{\mathrm{H}}\right)}\right)^{2 / 3} S^{1 / 3} .
\end{aligned}
$$

$\left\{n_{\mathrm{G}}^{\mathrm{iii} * *}(q), n_{\mathrm{I}}^{\mathrm{iii} * *}(q), n_{\mathrm{H}}^{\mathrm{iii} * *}(q)\right\}$ and the number of total stations in various $q$ are demonstrated in Figure 4, where parameters are $S=437 \mathrm{~km}^{2}, M=1,353 \times 10^{3}, b_{\mathrm{G}}=45 \times 10^{6}$ yen $/$ year, $b_{\mathrm{I}}=79 \times 10^{6}$ yen $/$ year, $b_{\mathrm{H}}=109 \times 10^{6}$ yen $/$ year, $k_{\mathrm{G}}=12,480$ yen $/($ year $\cdot \mathrm{km})$, $k_{\mathrm{H}}=15,600 \mathrm{yen} /($ year $\cdot \mathrm{km})$.

\section{Application to Yokohama City}

In this section, we apply the preceding models to an existing city. The city we selected in the article is Yokohama City in Japan. Activities of Yokohama City, parameter setting, and estimations are stated below. 

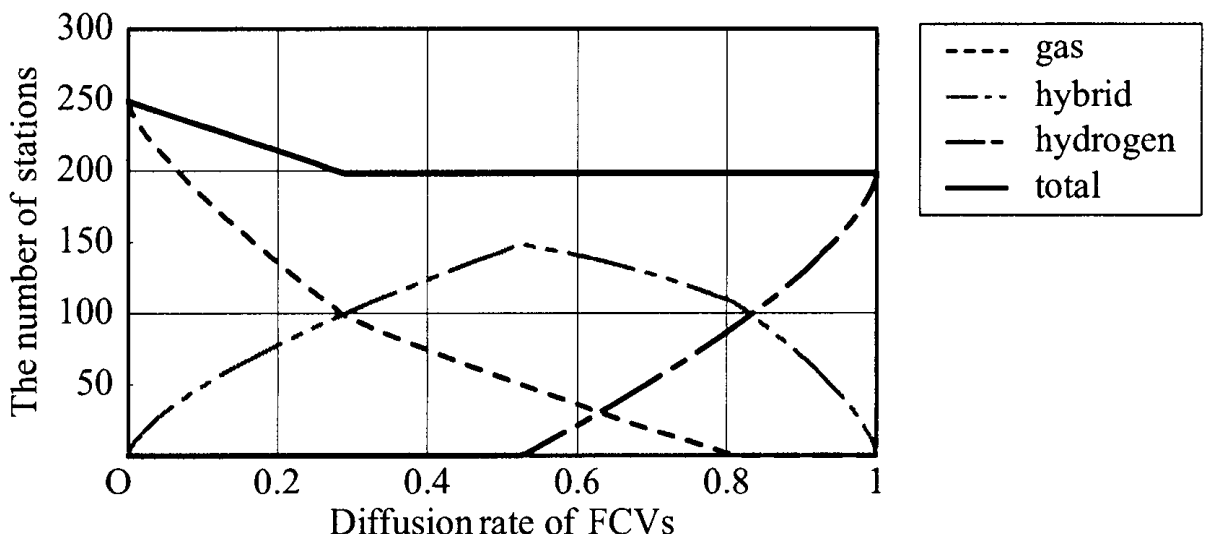

Figure 4: Optimal number of gas, hybrid and hydrogen stations (with total constraint)

\subsection{Activities of Yokohama City}

The municipality of Yokohama City declared "Environmentally Active City" in 2002, and has been struggling to resolve environmental problems positively. As a part of the struggle, the city also grapples with the realization of hydrogen society. One of the noteworthy things in relation to hydrogen is that a FCV was introduced as an official vehicle in 2004 [30]. It is the first example in a metropolitan area that a municipality has purchased a FCV. In addition, a number of events and symposiums about the environment and hydrogen have been held in Yokohama. "The World Hydrogen Energy Conference" in June 2004 is one example. In the conference, the mayor of Yokohama commented that he wanted to make the city of Yokohama a role model for hydrogen energy use [31]; This is a remarkable comment. Furthermore, three hydrogen stations have already been built in Yokohama by The Japan Hydrogen \& Fuel Cell Demonstration Project(JHFC) [11]. In consequence, it is said that Yokohama City is one of the most suitable regions for hydrogen society.

Together with these, the following facts support assumptions of the models. First of all, transportation efficiency is almost the same all over the region, because road network is sufficiently matured. Moreover, since population density is roughly uniform, it is expected that vehicle density is also uniform all over the region. These properties are confirmed by the locations of gas stations in Yokohama, which are also distributed relatively evenly (see Figure 5). Consequently, we choose Yokohama City as the region of study and apply the models in the following sections.

\subsection{Parameter setting}

Now, we would like to set parameters used in the model. Firstly, we define the parameters about the region, namely $S$ and $M$. According to The Geographical Survey Institute in Japan, the size of Yokohama City is $437.38 \mathrm{~km}^{2}$ [4]. Then we simply define $S=437 \mathrm{~km}^{2}$. While, the number of vehicles registered in Yokohama is 1,143,000 for private use and 42,000 for business use (according to The Kanto District Transport Bureau [12]). Now we must consider the frequency of use, because it must be different between private and business. We assume that a vehicle for business is used 5 times as frequently as that for private. It is equal to five private cars in terms of refueling. Thus, we define $M=(1,143+5 \times 42) \times 10^{3}=$ $1,353 \times 10^{3}$.

Next, we consider the parameters of stations $b_{\mathrm{G}}, b_{\mathrm{I}}$, and $b_{\mathrm{H}}$. To decide on them, we have to determine what is included in the operation cost of stations. In this study, we assume that the operation cost consists of employment cost and running cost of equipment. 


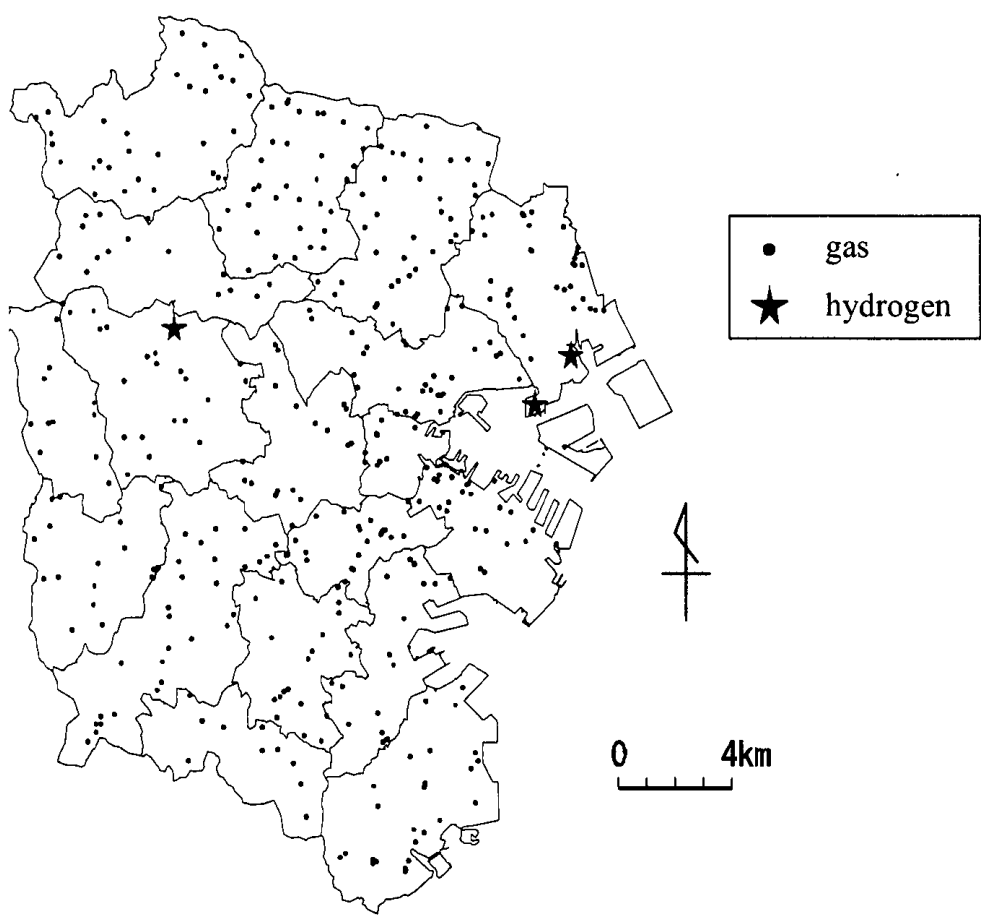

Figure 5: Map of Yokohama City

We assume that employment cost for each type of stations is commonly 15 million yen. It corresponds to the situation that 6 employees whose hourly wage is 800 yen work 8 hours per day. On the other hand, running cost of equipment depends on the type of station. According to The National Federation of Petroleum Commercial Association, the running cost of gas station is 2.3 million yen/month, although it is a case study of self-service gas station [17]. It is equal to 27.6 million yen/year. Thus, we assume that the running cost of gas stations is 30 million yen/year. The running cost of hydrogen stations is estimated as 64 million yen/year [1]. Generally, it is said that investment cost of hydrogen station is twice as expensive as that of a gas station, the preceding cost is presumable. In consequence, we set $b_{\mathrm{G}}=(15+30) \times 10^{6}=45 \times 10^{6}$ yen/year and $b_{\mathrm{H}}=(15+64) \times 10^{6}=79 \times 10^{6}$ yen $/$ year. As for hybrid stations, we assume that there is no common equipment between gas and hydrogen. Then, only employment cost will be saved and $b_{\mathrm{I}}=(15+30+64) \times 10^{6}=109 \times 10^{6}$ yen/year.

Finally, let us consider the parameters for transportation cost. To be more precisely, we must decide on $\alpha, \kappa, \nu_{\mathrm{G}}$, and $\nu_{\mathrm{H}}$. We assume that the transportation cost per unit distance $\alpha$ is 300 yen, which is equivalent to 4500 yen $/ \mathrm{h}$ if vehicle's speed is $15 \mathrm{~km} / \mathrm{h}$. For $\kappa$, it is well known that $\kappa$ is roughly 0.4 if Euclidean distance is assumed [14,15,25]. In addition, distance via road network is about 1.3 times as long as Euclidean distance [13]. Consequently, we set $\kappa=0.4 \times 1.3=0.52$. For $\nu_{\mathrm{G}}$, we assume that gasoline vehicles refuel every 10 days and set $\nu_{\mathrm{G}}=40$. While, FCVs need to refuel more frequently than gasoline vehicles, $\nu_{\mathrm{H}}=50$ is assumed. From the parameters stated above, we get $k_{\mathrm{G}}=2 \times 300 \times 0.52 \times 40=12,480$ yen $/($ year $\cdot \mathrm{km})$ and $k_{\mathrm{H}}=2 \times 300 \times 0.52 \times 50=15,600$ yen $/($ year $\cdot \mathrm{km})$.

\subsection{Estimation}

We calculated the optimal solution of each model (Section3.3, 3.4, 4.3, 4.4) assuming the preceding parameters. The results are shown in Figure 1, 2, 3, 4, which have already been demonstrated in the previous sections. The optimal number of gas stations before transition 
is estimated as 249, and it is roughly half as many as the number of gas stations in Yokohama City (465 stations at present). However, this fact should not prove to be a matter of concern, because some institutes point out that there are already too many gas stations in Japan (e.g. [17]). Hence, it is understandable that the socially optimal number of stations is fewer than the actual number.

Figure 6 indicates the total cost of each model. We calculate them by substituting the optimal solutions for the functions $T^{\mathrm{ii}}$ and $T^{\mathrm{iii}}$. From Figure 6, we can confirm for each model that the total cost takes the maximum value in the transition period.

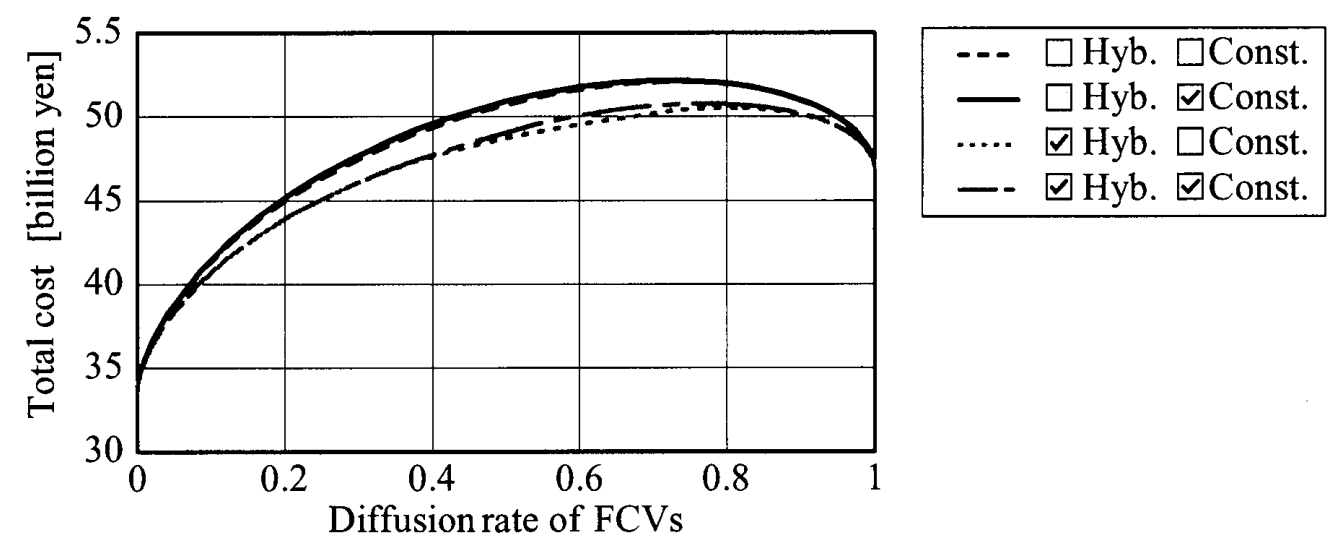

Figure 6: Total cost in each model

Next, let us analyze the difference among the four models. For this purpose, we calculate the ratio of total cost of each model to that of the model in Section 3.3, which does not consider the total number constraint and the existence of hybrid stations (see Figure 7). From this calculation, we can understand how the constraint and the introduction of hybrid stations affect the total cost: (i) the assumption of the total number constraint has little influence on the total cost (less than 1\%). (ii) the existence of hybrid stations reduces the total cost by $5 \%$.

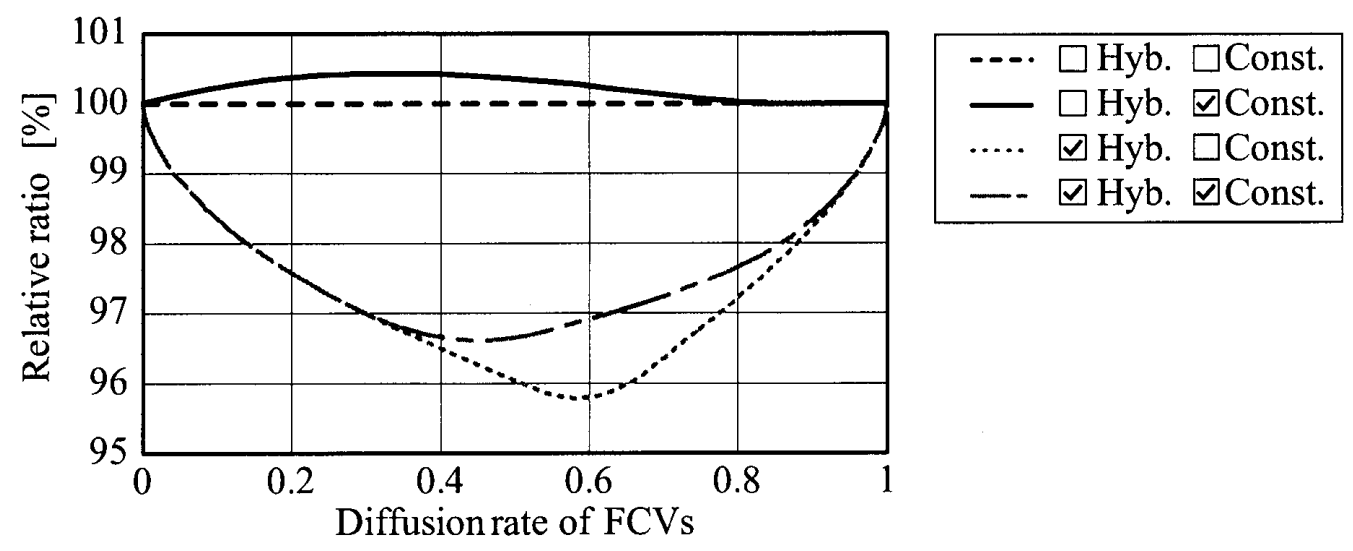

Figure 7: Relative ratio of total cost (total cost in Section3.3 $=100$ )

The discussion stated above can be summarized as follows:

[feature 5]

No matter which model is adopted, the maximum value of the total cost in the region is observed in the transition period. 


\section{[feature 6]}

The total cost is slightly affected by the total number constraint of stations, while the introduction of hybrid type has a certain amount of effect on the total cost.

\section{Conclusion}

In this paper, we focused on the optimal number of gas, hybrid, and hydrogen stations in a region where gasoline vehicles and FCVs are used. Especially, we considered the relationship of trade-off between operation cost of stations and transportation cost of vehicles. Assuming plausible parameters, we numerically clarified the following features.

1) If only gas and hydrogen stations are assumed, the optimal number of total stations in the transition period is greater than that before or after transition.

2) When gas, hybrid, and hydrogen stations are supposed simultaneously, the optimal number of total stations in the transition period is less than that before or after transition.

3) In the middle period of transition, it is optimal that all stations become hybrid type.

We also formulated the models which included the constraint of total number. Both upper and lower limitations represent some situations such as site, approval, and maintenance. In terms of reality, someone might consider that these constraints are questionable. It is true that there is important cost which is not considered in the models, namely construction and conversion cost of stations. Since this cost is not incorporated, the optimal number of total stations results in an unrealistic variation. If the construction cost of new stations is incorporated in the model, the number of total stations would not increase like Figure 1. Similarly, if conversion cost is much cheaper than construction cost, the number of total stations would not decrease like Figure 3 . However, this cost only affects the number of total stations, and does not influence the component ratio of each type. Therefore, we emphasize the simplicity of the models and append the constraints in the study. To solve the difficulty stated above, we have to incorporate with the concept of time explicitly. It would be an important study in the future.

In Section 5, we applied the models to Yokohama City. By setting various parameters, we proposed the optimal number of stations. These parameters however are not quite concrete. Hence, the solutions about Yokohama City contain some amount of uncertainty. This paper should be regarded as a study which clarifies the structure of the relation between FCVs and hydrogen stations rather than that which predicts the actual number of stations in the coming hydrogen society. We expect that the features indicated in the study are understood and utilized as a basic idea of hydrogen infrastructure in the future.

\section{A. Proof of the Convexity of $T^{\mathrm{ii}}$}

The Hessian matrix of $T^{\mathrm{ii}}\left(n_{\mathrm{G}}, n_{\mathrm{H}}\right)$ is calculated as follows:

$$
\nabla^{2} T^{\mathrm{ii}}=\left(\begin{array}{cc}
\frac{3 k_{\mathrm{G}}(1-q) M S^{1 / 2}}{4 n_{\mathrm{G}}^{3 / 2}} & 0 \\
0 & \frac{3 k_{\mathrm{H}} q M S^{1 / 2}}{4 n_{\mathrm{H}}^{3 / 2}}
\end{array}\right) .
$$

Then, $\lambda^{\mathrm{ii}}$, which denote the eigenvalues of $\nabla^{2} T^{\mathrm{ii}}$, are given by

$$
\lambda^{\mathrm{ii}}=\frac{3 k_{\mathrm{G}}(1-q) M S^{1 / 2}}{4 n_{\mathrm{G}}^{3 / 2}}, \frac{3 k_{\mathrm{H}} q M S^{1 / 2}}{4 n_{\mathrm{H}}^{3 / 2}} .
$$


Since all $\lambda^{\mathrm{ii}}$ are greater than 0 assuming $n_{\mathrm{G}}, n_{\mathrm{H}}>0$, it is proved that $T^{\mathrm{ii}}\left(n_{\mathrm{G}}, n_{\mathrm{H}}\right)$ is a convex function.

\section{B. Proof of the Convexity of $T^{\mathrm{iii}}$}

The Hessian matrix of $T^{\mathrm{iii}}\left(n_{\mathrm{G}}, n_{\mathrm{I}}, n_{\mathrm{H}}\right)$ is expressed as follows:

$$
\nabla^{2} T^{\mathrm{iii}}=\left(\begin{array}{ccc}
A & A & 0 \\
A & A+B & B \\
0 & B & B
\end{array}\right)
$$

where

$$
\begin{aligned}
A & =\frac{3 k_{\mathrm{G}}(1-q) M S^{1 / 2}}{4\left(n_{\mathrm{G}}+n_{\mathrm{I}}\right)^{3 / 2}}, \\
B & =\frac{3 k_{\mathrm{H}} q M S^{1 / 2}}{4\left(n_{\mathrm{I}}+n_{\mathrm{H}}\right)^{3 / 2}} .
\end{aligned}
$$

Then, $\lambda^{\text {iii }}$, which denote the eigenvalues of $\nabla^{2} T^{\mathrm{ii}}$, are given by

$$
\lambda^{\mathrm{ii}}=0, A+B-\sqrt{A^{2}-A B+B^{2}}, A+B+\sqrt{A^{2}-A B+B^{2}} .
$$

Now $A, B>0$ is assured if $n_{\mathrm{G}}+n_{\mathrm{I}}, n_{\mathrm{I}}+n_{\mathrm{H}}>0$, and

$$
(A+B)^{2}>A^{2}-A B+B^{2}>0 \quad(\because A, B>0)
$$

is obtained. Consequently, all $\lambda^{\mathrm{iii}}$ are greater than 0 , which means $T^{\mathrm{iii}}\left(n_{\mathrm{G}}, n_{\mathrm{I}}, n_{\mathrm{H}}\right)$ is a convex function.

\section{Derivation of the Optimal Solution in Section4.4}

In a similar manner to that of Section 4.3 , we obtain the optimal solution $\left\{n_{\mathrm{G}}^{\mathrm{iii**}}, n_{\mathrm{I}}^{\mathrm{iii} * *}, n_{\mathrm{H}}^{\mathrm{iii**}}\right\}$ by incorporating whether (4.13), (4.14), and (4.15) are active constraints or not.

However, the cases stated below are not adequate. First of all, when (4.13), (4.14), and (4.15) are all active constraints, $T^{\mathrm{iii}}\left(n_{\mathrm{G}}, n_{\mathrm{I}}, n_{\mathrm{H}}\right) \rightarrow+\infty$ because of $n_{\mathrm{G}}=n_{\mathrm{I}}=n_{\mathrm{H}}=0$. Similarly, when (4.13) and (4.14) are active constraints, or when (4.14) and (4.15) are active constraints, $T^{\mathrm{iii}}\left(n_{\mathrm{G}}, n_{\mathrm{I}}, n_{\mathrm{H}}\right) \rightarrow+\infty$ is obtained. Finally, when (4.14) is the only active constraint, $b_{\mathrm{I}}-b_{\mathrm{G}}-b_{\mathrm{H}}=\mu_{\mathrm{I}}>0$ is supposed because of $\mu_{\mathrm{G}}=\mu_{\mathrm{H}}=0$, (4.18), (4.19), and (4.20). This contradicts (4.1). Therefore, we get the optimal solution $\left\{n_{\mathrm{G}}^{\mathrm{iii**}}, n_{\mathrm{I}}^{\mathrm{iii} * *}, n_{\mathrm{H}}^{\mathrm{iii**}}\right\}$ for the following four cases.

\section{b-1) Constraint (4.15) is active [Former Period]}

In this case, we have

$$
n_{\mathrm{H}}^{\mathrm{ii} * *}(q)=0 .
$$

In addition, from (4.18) and $\mu_{\mathrm{G}}=0$, we get

$$
\lambda=b_{\mathrm{G}}-\frac{1}{2}(1-q) M k_{\mathrm{G}} S^{1 / 2}\left(n_{\mathrm{G}}+n_{\mathrm{I}}\right)^{-3 / 2} .
$$

By substituting the equations above and $\mu_{\mathrm{I}}=0$ for (4.19), we get

$$
n_{\mathrm{I}}^{\mathrm{iii} * *}(q)=\left(\frac{k_{\mathrm{H}} q M}{2\left(b_{\mathrm{I}}-b_{\mathrm{G}}\right)}\right)^{2 / 3} S^{1 / 3}
$$


Thus, from (4.21) and (C.2), we obtain

$$
n_{\mathrm{G}}^{\mathrm{iii} * *}(q)=N_{\text {low }}-\left(\frac{k_{\mathrm{H}} q M}{2\left(b_{\mathrm{I}}-b_{\mathrm{G}}\right)}\right)^{2 / 3} S^{1 / 3} .
$$

As $n_{\mathrm{G}}^{\mathrm{iii*}}(q) \geq 0$ should be satisfied, the following condition of $q$ is obtained from (C.3):

$$
q \leq \frac{2 N_{\mathrm{low}}^{3 / 2}\left(b_{\mathrm{I}}-b_{\mathrm{G}}\right)}{M S^{1 / 2} k_{\mathrm{H}}}
$$

Furthermore,

$$
\mu_{\mathrm{H}}=b_{\mathrm{I}}-b_{\mathrm{G}}+\frac{1}{2}(1-q) M k_{\mathrm{G}} S^{1 / 2} N_{\mathrm{low}}^{-3 / 2}
$$

is derived from (4.20) and (C.1). $\mu_{\mathrm{H}}>0$ is supposed as a KKT condition, then

$$
q \leq 1-\frac{2 N_{\text {low }}^{3 / 2}\left(b_{\mathrm{I}}-b_{\mathrm{H}}\right)}{M S^{1 / 2} k_{\mathrm{G}}}
$$

is set as the other condition of $q$.

\section{b-2) No Constraint is active [Middle Period 1]}

From $\mu_{\mathrm{G}}, \mu_{\mathrm{I}}=0,(4.18)$, and (4.19), we at first get

$$
n_{\mathrm{I}}^{\mathrm{iii} * *}(q)+n_{\mathrm{H}}^{\mathrm{iii} * *}(q)=\left(\frac{k_{\mathrm{H}} q M}{2\left(b_{\mathrm{I}}-b_{\mathrm{G}}\right)}\right)^{2 / 3} S^{1 / 3}
$$

Hence we obtain

$$
n_{\mathrm{G}}^{\mathrm{iii} * *}(q)=N_{\text {low }}-\left(\frac{k_{\mathrm{H}} q M}{2\left(b_{\mathrm{I}}-b_{\mathrm{G}}\right)}\right)^{2 / 3} S^{1 / 3}
$$

from (4.21), and (C.4). Similarly, the equation below is also obtained from $\mu_{\mathrm{I}}, \mu_{\mathrm{H}}=0$, (4.19), and (4.20):

$$
n_{\mathrm{G}}^{\mathrm{iii} * *}(q)+n_{\mathrm{I}}^{\mathrm{iii} * *}(q)=\left(\frac{k_{\mathrm{G}}(1-q) M}{2\left(b_{\mathrm{I}}-b_{\mathrm{H}}\right)}\right)^{2 / 3} S^{1 / 3} .
$$

Therefore, from (4.21) and (C.6),

$$
n_{\mathrm{H}}^{\mathrm{iij} * *}(q)=N_{\text {low }}-\left(\frac{k_{\mathrm{G}}(1-q) M}{2\left(b_{\mathrm{I}}-b_{\mathrm{H}}\right)}\right)^{2 / 3} S^{1 / 3}
$$

is deduced. Moreover, from (4.21), (C.5), and (C.7),

$$
n_{\mathrm{I}}^{\mathrm{iii} * *}(q)=\left\{\left(\frac{k_{\mathrm{H}} q M}{2\left(b_{\mathrm{I}}-b_{\mathrm{G}}\right)}\right)^{2 / 3}+\left(\frac{k_{\mathrm{G}}(1-q) M}{2\left(b_{\mathrm{I}}-b_{\mathrm{H}}\right)}\right)^{2 / 3}\right\} S^{1 / 3}-N_{\text {low }}
$$

is obtained. As $n_{\mathrm{G}}^{\mathrm{iij} * *}(q), n_{\mathrm{H}}^{\mathrm{iii} * *}(q) \geq 0$ is supposed,

$$
\frac{2 N_{\text {low }}^{3 / 2}\left(b_{\mathrm{I}}-b_{\mathrm{G}}\right)}{M S^{1 / 2} k_{\mathrm{H}}} \leq q \leq 1-\frac{2 N_{\text {low }}^{3 / 2}\left(b_{\mathrm{I}}-b_{\mathrm{H}}\right)}{M S^{1 / 2} k_{\mathrm{G}}}
$$

is derived as the condition of $q$ from (C.5) and (C.7). 


\section{b-3) Constraints (4.13) and (4.15) are active [Middle Period 2]}

In this case, we have

$$
\begin{aligned}
& n_{\mathrm{G}}^{\mathrm{iii**}}(q)=0, \\
& n_{\mathrm{H}}^{\mathrm{iii*}}(q)=0 .
\end{aligned}
$$

Then, from (4.21), we get

$$
n_{\mathrm{I}}^{\mathrm{iii**}}(q)=N_{\text {low }} .
$$

Now, by substituting the solution above and $\mu=0$ for (4.19), we derive

$$
\lambda=b_{\mathrm{I}}-\frac{1}{2} S^{1 / 2} N_{\mathrm{low}}^{-3 / 2}\left((1-q) M k_{\mathrm{G}}+q M k_{\mathrm{H}} S^{1 / 2}\right) .
$$

To satisfy the KKT conditions, $\mu_{\mathrm{G}}, \mu_{\mathrm{H}} \geq 0$ are supposed, then the following condition is derived from (4.18), (4.20), and (C.8):

$$
\frac{2 N_{\text {low }}^{3 / 2}\left(b_{\mathrm{I}}-b_{\mathrm{G}}\right)}{M S^{1 / 2} k_{\mathrm{H}}} \leq q \leq 1-\frac{2 N_{\text {low }}^{3 / 2}\left(b_{\mathrm{I}}-b_{\mathrm{H}}\right)}{M S^{1 / 2} k_{\mathrm{G}}} .
$$

b-4) Constraint (4.13) is active [Latter period]

In this case, we have

$$
n_{\mathrm{G}}^{\mathrm{iii} * *}(q)=0 .
$$

Furthermore, from $\mu_{\mathrm{H}}=0$ and (4.20), we get

$$
\lambda=b_{\mathrm{H}}-\frac{1}{2} q M k_{\mathrm{H}} S^{1 / 2}\left(n_{\mathrm{I}}+n_{\mathrm{H}}\right)^{-3 / 2} .
$$

By substituting these equations and $\mu_{\mathrm{I}}=0$ for (4.19), we obtain

$$
n_{\mathrm{I}}^{\mathrm{iii} * *}(q)=\left(\frac{k_{\mathrm{G}}(1-q) M}{2\left(b_{\mathrm{I}}-b_{\mathrm{H}}\right)}\right)^{2 / 3} S^{1 / 3} .
$$

Hence, from (4.21) and (C.10), we get

$$
n_{\mathrm{H}}^{\mathrm{iii} * *}(q)=N_{\text {low }}-\left(\frac{k_{\mathrm{G}}(1-q) M}{2\left(b_{\mathrm{I}}-b_{\mathrm{H}}\right)}\right)^{2 / 3} S^{1 / 3} .
$$

Since $n_{\mathrm{H}}^{\mathrm{iii} * *}(q) \geq 0$ is assumed, the following condition of $q$ is calculated:

$$
\frac{2 N_{\text {low }}^{3 / 2}\left(b_{\mathrm{I}}-b_{\mathrm{G}}\right)}{M S^{1 / 2} k_{\mathrm{H}}}<q .
$$

In addition,

$$
\mu_{\mathrm{G}}=b_{\mathrm{I}}-b_{\mathrm{H}}+\frac{1}{2} q M k_{\mathrm{H}} S^{1 / 2} N_{\mathrm{low}}^{-3 / 2}
$$

is obtained from (4.18) and (C.9). Assuming $\mu_{\mathrm{G}}>0$ as a KKT condition, we derive the other condition of $q$ as follows:

$$
1-\frac{2 N_{\text {low }}^{3 / 2}\left(b_{\mathrm{I}}-b_{\mathrm{G}}\right)}{M S^{1 / 2} k_{\mathrm{G}}} \leq q .
$$




\section{References}

[1] I. Akiyama, M. Chiba, and H. Yamamoto: Sugu Wakaru Nenryodenchi no Shikumi (KANKI Publishing, Tokyo, 2001). (in Japanese)

[2] V.F. Dökmeci: An optimization model for a hierarchical spatial system. Journal of Regional Science, 13 (1973), 439-451.

[3] A. Gore: An Inconvenient Truth: The planetary emergency of global warming and what we can do about it (Rodale, New York, 2006).

[4] Geographical Survey Institute in Japan: Zenkoku Todofuken Shikuchosonbetsu Mensekicho (Geographical Survey Institute in Japan, Tokyo, 2006). (in Japanese)

[5] S.M. Gusein-Zade: Alternative explanations of the dependence of the density of centers on the density of population. Journal of Regional Science, 33 (1993), 547-558.

[6] International Energy Agency: Hydrogen \& Fuel Cells: Review of national R\&D programs (OECD, Paris, 2004).

[7] International Energy Agency: World Energy Outlook 2004 (OECD, Paris, 2004).

[8] International Energy Agency: Prospects for Hydrogen and Fuel Cells: Energy technology analysis (OECD, Paris, 2005).

[9] P. Hoffmann: Tomorrow's Energy: Hydrogen, fuel cells, and the prospects for a cleaner planet (The MIT Press, Cambridge, 2001).

[10] Intergovernmental Panel on Climate Change: Climate Change 2001: Synthesis report (Cambridge University Press, Cambridge, 2001).

[11] Japan Hydrogen \& Fuel Cell Demonstration Project: Report on the 4th JHFC Seminar 2005 FY (JHFC, Tokyo, 2006).

[12] Kanto District Transport Bureau: Shichosonbetsu Jidosha Hoyusharyosu (the Ministry of Land Infrastructure and Transport, Tokyo, 2006). (in Japanese)

[13] T. Koshizuka and J.Kobayashi: On the relation between road distance and Euclidean distance. Journal of the City Planning Institute of Japan, 18 (1983), 43-48. (in Japanese)

[14] O. Kurita: A mathematical model on the optimal number of urban facilities: Empirical analysis on the number of the wards of the ordinance-designated cities in Japan. Journal of Architecture Planning and Environmental Engineering, 524 (1999), 169-176. (in Japanese)

[15] O. Kurita: A macro-scopic model of the optimal location of hydrogen station network: The optimal number of hydrogen stations and the numerical solution of gas pipeline. Journal of the City Planning Institute of Japan, 41 (2006), 193-198. (in Japanese)

[16] J.J. MacKenzie: Oil as a Finite Resource: When is global production likely to peak? (World Resources Institute, Washington D.C., 2000).

[17] National Federation of Petroleum Commercial Association: Sekiyuhanbaigyo Shoraizo Kenkyukai Hokokusho (National Federation of Petroleum Commercial Association, Tokyo, 2004). (in Japanese)

[18] G.L. Nemhauser, M.J. Todd, and A.H.G. Rinnooy Kan: Optimization (North-Holland, Amsterdam, 1989).

[19] D.S. Palmer: The placing of service points to minimize travel. Operational Research Quarterly, 24 (1973), 121-123.

[20] J. Rifkin: The Hydrogen Economy: The creation of the world-wide energy web and the redistribution of power on earth (Polity, Oxford, 2002). 
[21] B. Sorensen: Hydrogen and Fuel Cells: Emerging technologies and applications (Elsevier Academic Press, Burlington, 2005).

[22] G.E. Stephan: Territorial division: The least-time constraint behind the formation of subnational boundaries. Science, 196 (1977), 523-524.

[23] G.E. Stephan: The distribution of service establishments. Journal of Regional Science, 28 (1988), 29-40.

[24] T. Suzuki: A note on the optimal hierarchy system of the facilities. Journal of the City Planning Institute of Japan, 25 (1990), 331-336. (in Japanese)

[25] T. Suzuki: Theoretical relationship between facility density and population density determined by minimizing travel cost of users. Journal of Architecture Planning and Environmental Engineering, 521 (1999), 183-187. (in Japanese)

[26] H. Tanimura, H. Kaji, S. Ikeda, and T. Koshizuka: Toshi Keikaku Suri (Asakura Publishing, Tokyo, 1986). (in Japanese)

[27] P. Roberts: The End of Oil: On the edge of a perilous new world (Houghton Mifflin, 2004).

[28] D. Yergin: The Prize: The epic quest for oil, money, and power (Simon and Schuster, New York, 1992).

[29] Agency for Natural Resources and Energy: Suiso energy shakai no shoraizo (Ministry of Economy, Trade and Industry, Tokyo, 2004). (in Japanese) http://www.enecho.meti.go.jp/info/committee/nennryoudennchi/syouraizou.pdf

[30] City of Yokohama: City of Yokohama Web Page (City of Yokohama, Yokohama, 2007). http://www.city.yokohama.jp/en/

[31] Japan Hydrogen \& Fuel Cell Demonstration Project: Interview with Mr. Hiroshi Nakata (JHFC, Tokyo, 2004).

http://www.jhfc.jp/e/column/interview2.html

Osamu Kurita

Faculty of Science and Technology

Keio University

3-14-1, Hiyoshi, Kohoku-ku,

Yokohama 223-8522, Japan

E-mail: kurita@ae.keio.ac.jp 